The University of Maine

DigitalCommons@UMaine

8-20-2015

\title{
Spectral attenuation and backscattering as indicators of average particle size
}

Wayne Homer Slade

Sequoia Scientific, Inc.

Emmanuel Boss

University of Maine, emmanuel.boss@maine.edu

Follow this and additional works at: https://digitalcommons.library.umaine.edu/sms_facpub

Part of the Oceanography and Atmospheric Sciences and Meteorology Commons

\section{Repository Citation}

Slade, Wayne Homer and Boss, Emmanuel, "Spectral attenuation and backscattering as indicators of average particle size" (2015). Marine Sciences Faculty Scholarship. 165.

https://digitalcommons.library.umaine.edu/sms_facpub/165

This Article is brought to you for free and open access by DigitalCommons@UMaine. It has been accepted for inclusion in Marine Sciences Faculty Scholarship by an authorized administrator of DigitalCommons@UMaine. For more information, please contact um.library.technical.services@maine.edu. 


\title{
applied optics
}

\section{Spectral attenuation and backscattering as indicators of average particle size}

\author{
Wayne Homer Slade ${ }^{1, *}$ and Emmanuel Boss ${ }^{2}$ \\ ${ }^{1}$ Sequoia Scientific, Inc., 2700 Richards Road, Suite 107, Bellevue, Washington 98005, USA \\ ${ }^{2}$ School of Marine Sciences, University of Maine, Orono, Maine 04469, USA \\ *Corresponding author: wslade@sequoiasci.com
}

Received 23 April 2015; revised 7 July 2015; accepted 19 July 2015; posted 20 July 2015 (Doc. ID 239602); published 12 August 2015

\begin{abstract}
Measurements of the particulate beam attenuation coefficient at multiple wavelengths in the ocean typically exhibit a power law dependence on wavelength, and the slope of that power law has been related to the slope of the particle size distribution (PSD), when assumed to be a power law function of particle size. Recently, spectral backscattering coefficient measurements have been made using sensors deployed at moored observatories, on autonomous underwater vehicles, and even retrieved from space-based measurements of remote sensing reflectance. It has been suggested that these backscattering measurements may also be used to obtain information about the shape of the PSD. In this work, we directly compared field-measured PSD with multispectral beam attenuation and backscattering coefficients in a coastal bottom boundary later. The results of this comparison demonstrated that (1) the beam attenuation spectral slope correlates with the average particle size as suggested by theory for idealized particles and PSD; and (2) measurements of spectral backscattering also contain information reflective of the average particle size in spite of large deviations of the PSD from a spectral power law shape. (C) 2015 Optical Society of America
\end{abstract}

OCIS codes: (010.1350) Backscattering; (010.4450) Oceanic optics; (010.4458) Oceanic scattering; (290.1350) Backscattering; (290.2200) Extinction; (290.5850) Scattering, particles.

http://dx.doi.org/10.1364/AO.54.007264

\section{INTRODUCTION}

The particle size distribution (PSD) is a fundamental property of particle assemblages in natural waters and is important in a variety of marine sciences. For example, the PSD can aid in the comprehension of phytoplankton community dynamics [1] and sediment transport [2]. Measurements of PSD for particles in the approximate size range of 1 to $100 \mu \mathrm{m}$ are typically made on discrete water samples (e.g., a Coulter counter), are timeconsuming, and have the additional problem of disturbing the in situ size distribution, such as by breaking aggregates. More recently, in-water instruments for particle sizing using near-forward laser diffraction have been used in a variety of applications [1,3-12].

To better understand natural processes at a broad range of time and space scales, a great deal of effort within the oceanographic community is being spent adapting sensors for platforms such as gliders, profiling floats, and moorings $[13,14]$. In situ optical sensors possess a number of characteristics that make them ideal for autonomous platforms. Most notable is their high sampling rate and low power consumption. Furthermore, measurements of inherent optical properties (IOPs), such as the particulate beam attenuation coefficient, $c_{p}(\lambda)\left(\mathrm{m}^{-1}\right)$, and the backscattering coefficient, $b_{b p}(\lambda)\left(\mathrm{m}^{-1}\right)$, have been proposed as proxies for a number of environmental water properties, ranging from phytoplankton biomass $[15,16]$ to underwater visibility $[17,18]$. This paper investigates the use of these IOP measurements to yield information about the PSD.

Oceanic PSDs, expressed as number size distributions, $N(D)$ (number of particles per unit volume per unit particle size; common units of $\mathrm{L}^{-1} \mu \mathrm{m}^{-1}, \mathrm{~m}^{-3} \mu \mathrm{m}^{-1}$, or $\mathrm{m}^{-4}$ ), are often approximated as a number PSD power law function of diameter, $D(\mu \mathrm{m})$,

$$
N(D) \sim D^{-J},
$$

where $J$ is the (dimensionless) PSD power law slope [19]. PSD slopes usually range from around 2.5 to 5 , with 4 being a typical oceanic value [20-24]. Other more realistic PSD models have been used that include multiple power law slopes for different size ranges [25], roll-off of particles above or below a specified size [26], and a superposition of two generalized gamma functions combining biologically and terrestrially derived material [27]. However, many (especially energetic coastal) environments are poorly described by these simple models, leading to significant errors in modeling optical properties from the PSD [24]. Rather than pursuing an exact 
description of the PSD, in many cases it is sufficient and informative to quantify the PSD and its changes by focusing on parameters such as median particle size or other nonparametric descriptors of the PSD [28].

Measurements of the particulate beam attenuation coefficient in the ocean typically exhibit an inverse power law dependence on wavelength, $\lambda(\mathrm{nm})$, as

$$
c_{p}(\lambda) \sim \lambda^{-\gamma} .
$$

Based on theoretical derivation (assuming nonabsorbing spheres), the spectral slope, $\gamma$ (dimensionless), has been shown to be linearly related to the power law slope of the PSD, i.e., $\gamma \approx J-3$ [29-31]. Boss et al. [32] presented a dataset of $\gamma$ measurements from an optical profiling package and a limited number of PSD slopes from Coulter counter analysis of collocated (but not coincident) rosette bottle samples. Their finding that both the spectral slope and PSD slope were strongly correlated supports the theoretically derived link between $\gamma$ and PSD slope, J. With appropriate consideration for absorption and extremes of particle size distribution [31], the relation appears applicable to a wide range of oceanic particles.

Availability of particulate backscattering measurements as remotely sensed ocean color products, as well as from multispectral backscattering sensors deployed in situ and on autonomous platforms, has raised the question of whether or not the spectral shape of backscattering, $\gamma_{b b}$ (dimensionless) in $b_{b p}(\lambda) \sim$ $\lambda^{-\gamma_{b b}}$ (e.g., [33-35]), is an indicator of particle size in a similar manner to $\gamma$. While spectral beam attenuation typically exhibits smooth power law dependence on wavelength, absorption by natural particles is expected to cause deviation from the power law spectral shape of scattering and backscattering due to a combination of effects: (1) incident photons absorbed by particles will not be elastically scattered, and (2) anomalous dispersion in strong absorption bands [36-38]. We expect the effects of anomalous dispersion to play little role in the present study due to the lack of pronounced absorption peaks in our measurements and because they will tend to be averaged out due to the wide spectral bandwidths (approximately $10-20 \mathrm{~nm}$ FWHM) of currently available backscattering sensors [38].

To the best of our knowledge, no direct comparison of in situ spectral backscattering and PSD exists in the literature. However, using an inversion model to retrieve $b_{b p}(\lambda)$ from satellite ocean color data, Loisel et al. [39] computed global maps of $\gamma_{b b}$ and found them to compare well with expectations of the domination by small particles (e.g., picoplankton and colloids) in the subtropical gyres and by larger particles in coastal, upwelling, and high latitude regions. Kostadinov et al. [40] used a similar approach, with a Mie-based model linking the PSD slope and $\gamma_{b b}$. In a follow-on study, Kostadinov et al. [41] used this approach to examine particle (i.e., phytoplankton) size distribution in the open ocean (i.e., pico-, nano-, and micro-plankton stocks) and also found seasonal and gyre-scale spatial trends in line with the most probable size distributions.

\section{A. Overview of the Study}

As discussed above, there is a great interest in the use of the spectral beam attenuation coefficient, and especially the spectral backscattering coefficient, to characterize the shape of the
PSD in the ocean, while there exists little in situ data to support or refute such an idea. In general, it is not the attenuation or backscattering data that are lacking, as they have been commonly measured in ocean optical studies since the introduction of the ac-9 (WET Labs, Inc., Philomath, Oregon, http://www .wetlabs.com) and Hydroscat (HOBI Labs, Inc., Bellevue, Washington, http://www.hobilabs.com) instruments, followed by the ECO BB (WET Labs) sensors. It is rather measurements of the oceanic PSD coincident with measurements of multispectral optical properties that are far less common.

In the present study, we employed datasets where spectral attenuation and backscattering coefficients, and laserdiffraction-based PSD from a LISST-100X particle sizer (Sequoia Scientific, Inc., Bellevue, WA, http://www.sequoiasci .com) were measured coincident and collocated, in situ. Our observed PSD did not exhibit power law behavior. Thus, we summarized variability in the PSD using an average particle diameter. We then examined the relationship between the power law spectral shape of particulate beam attenuation and the PSD average diameter. Unsurprisingly, our measurements of the backscattering spectra did not exhibit the same smooth power-law-like behavior of the attenuation spectra. Instead, the spectra were characterized by a broad maximum in the region of 500-600 nm. In spite of the spectral shape, we applied the power law model to $b_{b p}(\lambda)$ spectra for comparison with average particle size, and then similarly examined the relationship between the spectral slope of particulate backscattering and average particle size. Based on measurements of spectral backscattering and scattering coefficients, we also examined the spectral nature of the particulate backscattering ratio.

\section{METHODS}

\section{A. Field Deployments}

Field measurements of spectral backscattering, spectral particulate attenuation, and particle size were made as part of the Optics Acoustics and Stress In Situ (OASIS) project at the Woods Hole Oceanographic Institution Martha's Vineyard Coastal Observatory (MVCO) during September-October of 2004, 2005, 2007, 2009, and 2011.

The MVCO subsea node [42] is located south of Edgartown, Martha's Vineyard (Massachusetts, http://www .whoi.edu/mvco) on the $12 \mathrm{~m}$ isobar. The seafloor in this region consists of shore-perpendicular swaths of alternating course and fine sand. There is strong tidal forcing $(\sim 1.5 \mathrm{~m}$ spring tidal range) that leads to east-west advection along the south shore of Martha's Vineyard. Wave forcing is dominated by southerly waves, with wave heights typically highest from late summer to spring, especially during large wave events associated with the passage of tropical storms and hurricanes in the Atlantic. Our selection of the months of September and October for the OASIS experiment was rooted in capturing these "fall transition" storms [43-45]. Significant wave heights and near-bottom currents were inferred by a $1200 \mathrm{kHz}$ Workhorse Monitor (Teledyne RD Instruments, Inc., Poway, California, http://www.rdinstruments.com) acoustic Doppler current profiler deployed as part of the core MVCO instrumentation at the node. 
Here we used data from the 2007 and 2009 deployments as detailed below. These years were chosen because they comprised a core set of instrumentation including a LISST100X particle sizer, a $10 \mathrm{~cm}$ pathlength ac-9 spectral absorption and attenuation meter (WET Labs), and an ECO BB9 spectral backscattering meter (WET Labs). Each year we deployed the instrumentation on a tripod, with sampling volumes at $1.2 \mathrm{~m}$ above bottom. The instrumentation was powered by, and data were delivered to, onshore computing facilities via the MVCO subsea node. All measured data were merged and binned into 5 min intervals for analysis.

The OASIS 2007 deployment ran from 2 to 24 September (yearday 245 to 267). To minimize possible effects of biofouling, diver operations were conducted for the cleaning of optical surfaces and changing of the ac-9 cartridge filter [46] on yearday 253. The OASIS 2007 dataset used in this study consists of measurements made between yearday 255 and 261 (Fig. 1), during which there were two storm-induced resuspension events associated with the remains of Tropical Storm Gabrielle. The BB9 ran on a 2:3 minute on:off duty cycle to reduce attraction of phototactic organisms. The BB9 gain was changed at the factory to reduce severe saturation issues observed during OASIS 2005. Absorption data during this deployment were not available due to an improperly fitted ac-9 a-tube.

The OASIS 2009 campaign consisted of two separate deployments, 25 September to 2 October (yearday 268 to 275 ) and 16 to 22 October (yearday 289 to 295), with each deployment characterized by the passage of a storm system resulting in a significant dynamic range in physical forcing. The tripod was recovered and serviced between deployments, and diver operations for cleaning optical surfaces and replacing ac-9 filter cartridge were conducted on yearday 292. Data from the ac-9 were not available during the first deployment due to power supply issues that were resolved before the redeployment; in this analysis we focused on the second deployment between yearday 289 to 295 (Fig. 2). Similar to the 2007 deployment, the BB9 was run on a 1:4 minute on:off duty cycle.

\section{B. LISST-100X Particle Size Distribution Measurements}

The LISST-100X in situ particle sizing instruments operate on the principle of laser diffraction [3]. In short, a collimated laser beam $(670 \mathrm{~nm})$ illuminates a sample volume where it is scattered through a Fourier lens toward receiving optics consisting of a pinhole and photodiode transmission detector (for the estimation of beam attenuation) surrounded by a set of 32 coplanar and concentric ring-shaped detectors. Because particle scattering is highly peaked in the near forward, the ring edge radii increase logarithmically. This covers an angle range of approximately $0.08-15^{\circ}$ or $0.04-7.5^{\circ}$ (in water), for the LISST100X Type-B and $-\mathrm{C}$ instruments, respectively. Particles that are small compared with the illuminating wavelength tend more toward isotropic scattering, while larger particles tend toward scattering in the near forward (i.e., diffraction). This basic physical premise is used in an inversion algorithm to estimate the PSD from the pattern of scattered light [47].

The laser diffraction particle sizing method is widely used and covered by ISO standards in industry [48] and has been
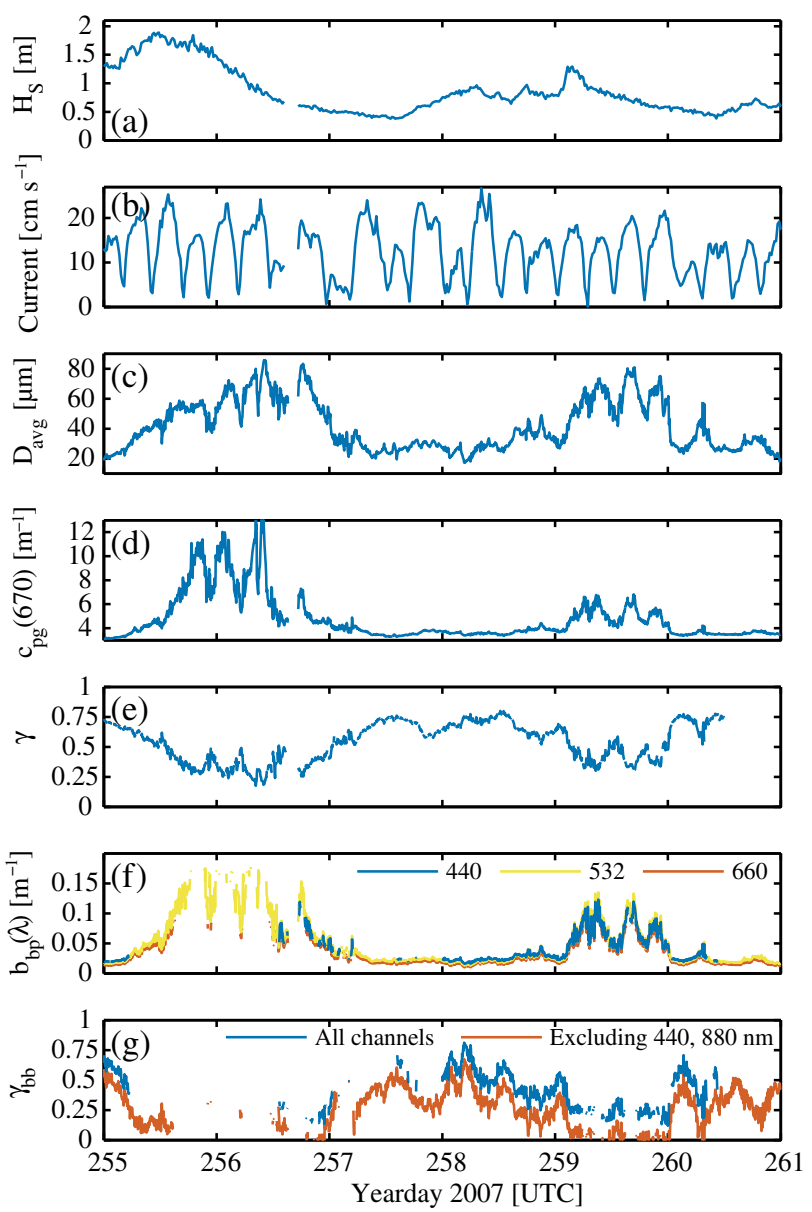

Fig. 1. Time series of OASIS 2007 deployment. (a) Significant wave height derived from ADCP surface velocity spectra; (b) current magnitude at $3.2 \mathrm{~m}$ above bottom, derived from ADCP; (c) average particle size, $D_{\text {avg }}$, and (d) beam attenuation, $c_{p g}(670)$, from the LISST-100X; (e) spectral slope, $\gamma$, derived from the ac-9; (f) particle backscattering, $b_{b p}(\lambda)$, at $\lambda=440,532$, and $660 \mathrm{~nm}$; and (g) spectral slope of backscattering, $\gamma_{b b}$. Gaps in $b_{b p}(\lambda)$ and $\gamma_{b b}$ are either due to saturation of the $\mathrm{BB}$ 9 backscattering sensor during strong resuspension or corrupted measurements (the instrument output was same as the dark reading) in the $440 \mathrm{~nm}$ channel during yearday from $\sim 255.25$ to 256.5 and from $\sim 257$ to 258 . Spectral slope, $\gamma_{b b}$, is shown (red) using a power law fit excluding the 440 and $880 \mathrm{~nm}$ channels; these $\gamma_{b b}$ are biased low compared to the fit with all wavelengths and are not used in the comparison between $\gamma_{b b}$ and $D_{\text {avg }}$.

evaluated (compared with other sizing methods such as Coulter, microscopy, and sieving) with natural suspensions, sorted sediment, phytoplankton cultures, as well as traceable size standards in both lab and in situ studies $[1,9,24,49]$. In general, several artifacts in the LISST-100X PSD can be considered. First, measurements of highly modal size distributions such as microsphere standards are able to accurately resolve the peak of the distribution but will be wider due to the nature of the inversion algorithm. Similarly, the peaks of multimodal particle size distributions are accurately resolved as long as the peaks are sufficiently separated and the particle aspect ratios are near one; for size distribution modes that are very close (usually less than a few size bins, depending on the algorithm 

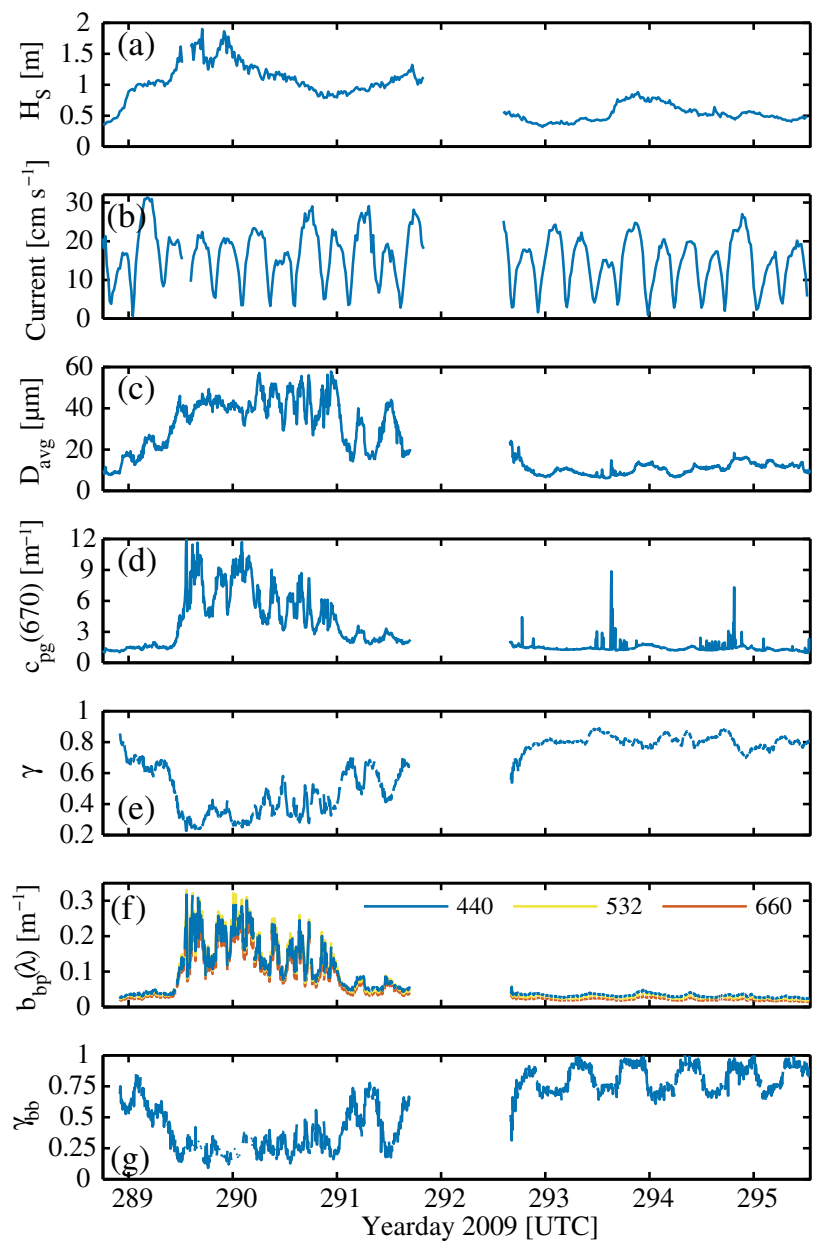

Fig. 2. Time series of the second OASIS 2009 deployment. Descriptions as in Fig. 1.

and particle matrix used), the inverted PSD will appear smeared. Second, for highly nonspherical particles, the inverted PSD can indicate modes corresponding to features of the nonspherical particles (for example, the PSD for algal cultures of Ceratium longipes with modes corresponding to a spheroid enclosing the entire body of the cell, the central body without horns, and the width of the horns [1]). Third, particles outside of the designed measurement range can cause rising tails in the inverted PSD.

LISST-100X data were processed in MATLAB (The MathWorks, Inc., Natick, Massachusetts, http://www .mathworks.com) using the manufacturer-provided protocols and inversion routine, yielding an estimate of volumetric PSD, $V(D)\left(\mu \mathrm{LL}^{-1}\right)$. Empirical inversion matrices based on nonspherical sediment particles were used [50], yielding particle size distribution having 32 bins with medians spanning 1.09-184 $\mu \mathrm{m}$ (Type-B) and 2.06-357 $\mu \mathrm{m}$ (Type-C). The nonspherical sediment inversion matrices are typically found to be less affected by particles outside of the measurement range $[50,51]$.

Optical properties in the geometric optics regime and the laser diffraction method are more related to areal size distribution (total cross sectional area for a given size bin per volume),
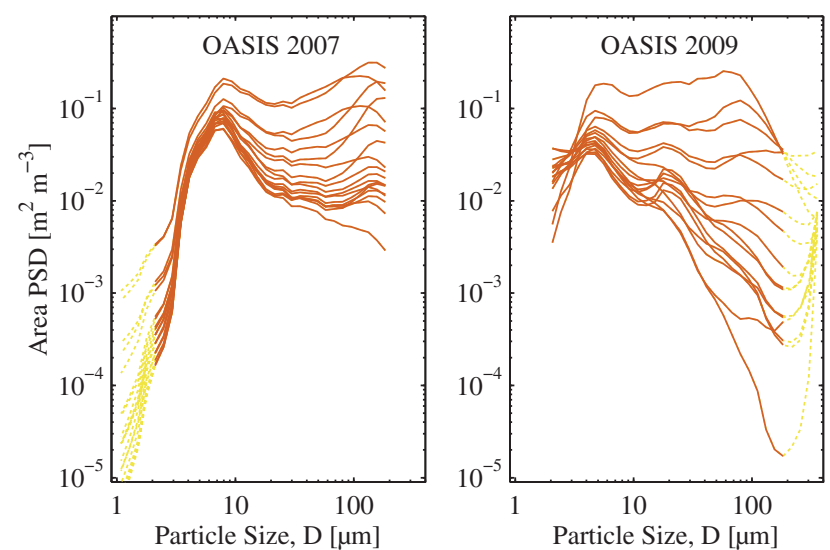

Fig. 3. Area particle size distributions for OASIS 2007 and 2009 deployments. Different LISST-100X instruments (Type-B and -C) with different size ranges were deployed in 2007 and 2009. Full instrument size spectra are shown in broken yellow, and the common size range used in the calculation of $D_{\text {avg }}$ is shown in solid red. The PSDs were calculated using the manufacturer-provided nonspherical particle inversion.

so we convert $V(D)$ to area distribution, $A(D)\left(\mathrm{m}^{2} \mathrm{~m}^{-3}\right)$, based on the assumption of spherical geometry. Our observed PSDs were generally not well represented as power law functions of size (Fig. 3), similar to recent observations by Reynolds et al. in coastal waters [24]. Therefore, we used the PSD data to calculate an average particle size $[31,52]$, based on the particle crosssectional area size distribution,

$$
D_{\text {avg }}=\frac{\sum_{i} A\left(D_{i}\right) D_{i}}{\sum_{i} A\left(D_{i}\right)}
$$

Type-B and Type-C instruments were deployed in 2007 and 2009 , respectively. Due to the difference in size ranges between the two instruments, the set of bins used in calculating $D_{\text {avg }}$ was reduced to the size range common between the two instruments, $\sim 2-184 \mu \mathrm{m}$ (solid red line in Fig. 3). In addition, beam attenuation due to particles and dissolve material at $670 \mathrm{~nm}, c_{p g}(670)$, was derived from the LISST-100X measurements (acceptance angles in water of $0.026^{\circ}$ and $0.013^{\circ}$ for the Type- $B$ and $-C$ instruments).

\section{C. ac-9 Absorption and Attenuation Measurements}

Measurements of attenuation and absorption were made using a WET Labs ac-9 combination spectral beam transmissometer and reflecting tube absorption meter, measuring attenuation and absorption at nine wavelengths, $\lambda=$ $[412,440,488,510,532,555,650,676$, and 715$] \mathrm{nm}$, at $6 \mathrm{~Hz}$ [53]. The same $10 \mathrm{~cm}$ pathlength ac-9 was used during all field campaigns, in each case deployed with an automated valve system to make periodic measurements on samples drawn through a large surface area $0.2 \mu \mathrm{m}$ filter cartridge (GE Osmonics Memtrex Nylon, $0.64 \mathrm{~m}^{2}$ filtration area), and contained in a diver-replacable fixture. The automated valve system was powered via the MVCO node and programmed to take filtered measurements for five minutes each hour, allowing for the 
calculation of calibration- and drift-independent particulate attenuation and absorption measurements [46].

For each measured particulate attenuation spectra $c_{p}(\lambda)$, a power law fit Eq. (2) was made using an unconstrained nonlinear optimization procedure (MATLAB fminsearch, the Nelder-Mead method).

Particulate absorption spectra $a_{p}(\lambda)$ were calculated from the measured absorption $a_{p, m}(\lambda)$ using the "proportionale" scattering correction presented in Röttgers et al. [54]:

$$
a_{p}(\lambda)=a_{p, m}(\lambda)-\left(a_{p, m}(715)-a_{715}\right)\left(\frac{e_{c}^{-1} c_{p}(\lambda)-a_{p, m}(\lambda)}{e_{c}^{-1} c_{p}(715)-a_{715}}\right),
$$

where $a_{715}=0.212 a_{p, m}(715)^{1.135}$ and $e_{c}=0.56$.

\section{BB9 Backscattering Measurements}

The WET Labs ECO BB9 measures the volume scattering function $\beta(\lambda, \theta)$ at a single angle in the backward direction, $\theta \approx 124^{\circ}$, at nine illumination wavelengths, $\lambda=[400,440$, $488,510,532,595,660,715$, and 880$] \mathrm{nm}$, at a $6 \mathrm{~Hz}$ sampling rate. Raw instrument data, $\operatorname{raw}(\lambda)$, were processed according to standard protocols as follows. The total volume scattering for each wavelength channel was calculated as

$$
\beta\left(\lambda, 124^{\circ}\right)=s(\lambda)[\operatorname{raw}(\lambda)-d(\lambda)] K(\lambda),
$$

where $s(\lambda)$ and $d(\lambda)$ are manufacturer-supplied scaling factors and dark offsets, respectively. BB9 calibration was performed by the manufacturer before each OASIS campaign (20 June 2007 and 26 Aug 2009) using a concentration series of $2 \mu \mathrm{m}$ beads (uncertainties in the calibration are examined in Appendix A).

The attenuation correction factor, $K(\lambda)$, in Eq. (5) corrects for the loss of photons within the instrument pathlength $[55,56]$ :

$$
K(\lambda)=\exp \left(L a_{p g}(\lambda)\right),
$$

where $a_{p g}(\lambda)$ is the combined absorption due to particles and dissolved materials $\left[a_{p g}(\lambda)=a_{p}(\lambda)+a_{g}(\lambda)\right]$, and $L$ is the effective pathlength. The correction includes only $a_{p g}(\lambda)$, assuming that losses due to water absorption and particle scattering are accounted for in the calibration procedure. For an ECO BB sensor with a centroid angle of $\theta \approx 124^{\circ}, L \approx 0.015 \mathrm{~m}$ [56].

Dissolved absorption, $a_{g}(\lambda)$, measurements were not available during the 2009 OASIS campaign (due to the use of the calibration and biofouling independent differencing technique). Previous ac-9 measurements during OASIS 2005 indicated that dissolved absorption was nearly constant: $a_{g}(\lambda) \approx a_{g}(440) \exp \left(-S_{g}(\lambda-440)\right)$, with $a_{g}(440) \approx 0.12 \mathrm{~m}^{-1}$ and $S_{g} \approx 0.014$, and neither $a_{g}(440)$ nor $S_{g}$ covarying with $a_{p}(\lambda)$ during resuspension events of $a_{p}(440)>2 \mathrm{~m}^{-1}$. Additionally, uncalibrated dissolved absorption $(440 \mathrm{~nm})$ from 2009 also appeared constant $(<1 \%$ MAD) and uncorrelated with particulate absorption. Thus, we assumed a constant dissolved absorption background to calculate $a_{p g}(\lambda)$ for the purpose of BB9 correction, for both the 2007 and 2009 deployments.

No absorption data (particulate or dissolved) were available in 2007. Therefore, we used a linear model vicariously estimating the correction factor using measured LISST-100X attenuation data, where the regression parameters $\rho_{0}(\lambda)$ and $\rho_{1}(\lambda)$ were determined from 2009 data (where absorption data and LISST-100X attenuation data were both available) using type-2 major axis regression [57],

$$
K(\lambda)=\rho_{1}(\lambda) c_{p g, \mathrm{LISST}}(670)+\rho_{0}(\lambda) .
$$

Based on 2009 data used for the regressions, the model was able to estimate the correction factor to within $<1 \%$ RMSE for all wavelengths. Given the relative consistency in interrelationships between the absorption and scattering observed during the 2005 and 2009 datasets, uncertainty in the application of the model to 2007 data is expected to be similar.

The correction factors, $K(\lambda)$, applied to the data used in the analysis (i.e., no bad or saturated channels) were at most $\sim 1.05$ and $\sim 1.04$ at $400 \mathrm{~nm}$, for 2007 and 2009 data, respectively, and decreased approximately exponentially with increasing wavelength, approaching unity in the red-NIR. In reality, the scattering phase functions of field measurements and calibration microspheres also differs substantially. This leads to additional uncertainty in the attenuation correction of $\beta\left(\lambda, 124^{\circ}\right)$ not explicitly considered here. However, total uncertainty in the attenuation correction is expected to be minor compared to the observed variability in $\gamma_{b b}$.

For correction of the BB9 data which had some different wavelength channels than the ac- $9, a_{p}(\lambda)$ and $c_{p}(\lambda)$ were linearly interpolated to the BB9 wavelengths at $\lambda=595$ and $660 \mathrm{~nm}$; and the 400 and $880 \mathrm{~nm}$ channels were extrapolated by linear fit to $\log a_{p}(\lambda)$ for $\lambda=412$ and $440 \mathrm{~nm}$ and $\lambda=555,650$, and $715 \mathrm{~nm}$, respectively. Note that $a_{p}(676)$ was not used for interpolation or extrapolation due to the chlorophyll absorption peak.

The particulate backscattering coefficient, $b_{b p}(\lambda)\left(\mathrm{m}^{-1}\right)$, was estimated from $\beta\left(\lambda, 124^{\circ}\right)$ as

$$
b_{b p}(\lambda)=2 \pi \chi_{p}\left(124^{\circ}\right)\left[\beta\left(\lambda, 124^{\circ}\right)-\beta_{\text {sw }}\left(\lambda, 124^{\circ}\right)\right],
$$

where $\chi_{p}\left(124^{\circ}\right)$ is a spectrally independent nondimensional factor relating the particulate backscattering coefficient to volume scattering at $124^{\circ}$ in the backward direction [58-60] and $\beta_{\text {sw }}\left(\lambda, 124^{\circ}\right)$ is the volume scattering coefficient of seawater $[61,62]$. Based on Sullivan et al. [56], we assumed $\chi_{p}\left(124^{\circ}\right)=1.08$.

Spectra typically exhibited a broad maximum in the bluegreen (450-550 nm, see Fig. 7), similar to observations by McKee et al. [63] in inorganic-dominated UK coastal waters, also using a BB9 instrument. In the OASIS 2007 and 2009 datasets considered here, saturation of instrument channels was problematic during resuspension events, even after having instrument gains adjusted before field campaigns in 2007 and 2009. Typically, saturation progressed from the NIR to the green as the particle load increased, but saturation was also sometimes problematic in the blue channels. Power law functions of the form of Eq. (2), i.e., $b_{b p}(\lambda) \sim \lambda^{\gamma b b}$, were fit to measured backscattering spectra, using all wavelength channels and the same unconstrained nonlinear optimization code used for spectral beam attenuation. Uncertainty in the backscattering spectral slope was estimated using a Monte Carlo model (see Appendix A). 


\section{E. Optical Proxies for Particle Composition}

Several optical proxies for particle composition were calculated in order to show the range of particle types included in our examination of spectral IOPs and particle size:

(i) The particulate single scattering albedo, $\bar{\omega}_{p}(\lambda)$, defined by

$$
\bar{\omega}_{p}(\lambda)=\frac{b_{p}(\lambda)}{c_{p}(\lambda)}=\frac{b_{p}(\lambda)}{a_{p}(\lambda)+b_{p}(\lambda)},
$$

is the probability that a photon will be scattered rather than absorbed in an interaction. When attenuation is mostly due to scattering, $\bar{\omega}_{p}(\lambda)$ is near one, and when it is dominated by absorption, $\bar{\omega}_{p}(\lambda)$ is near zero. Spectra of $\bar{\omega}_{p}(\lambda)$ are lowest in the blue wavelengths due to absorption by phytoplankton and nonalgal particles-even highly scattering minerals have characteristic absorption highest in the blue and decreasing toward the red [64]. Second-order spectral variation in $\bar{\omega}_{p}(\lambda)$ is due to absorption by algal pigments, typified by chlorophyll which causes a decrease at $\bar{\omega}_{p}(676)$, as well as a shoulder at $\bar{\omega}_{p}(440)$.

(ii) Chlorophyll concentration was calculated based on the absorption line height [65] as

$$
\mathrm{CHL}_{\mathrm{LH}}=\frac{1}{0.0104}\left(a_{p}(676)-a_{\mathrm{BL}}(676)\right)\left[\mathrm{mg} \mathrm{m}^{-3}\right] \text {, }
$$

where the baseline absorption at $676 \mathrm{~nm}, a_{\mathrm{BL}}(676)$, is calculated by linear interpolation of $a_{p}(\lambda)$ between $a_{p}(650)$ and $a_{p}(715)$.

(iii) The particle backscattering ratio, $\tilde{B}_{p}=b_{b p}(\lambda) / b_{p}(\lambda)$, was calculated for all BB9 wavelengths, using the extrapolated and corrected ac-9 scattering measurements. This ratio provides a proxy for the bulk index of refraction and thus the organic versus inorganic composition of the suspended particles [66]. It has also been shown to be correlated with the ratio of chlorophyll to beam attenuation, indicating dominance of phytoplankton $(\tilde{B} \sim 0.005)$ versus inorganic particles $(\tilde{B} \sim 0.02)$ [55]. Due to the lack of absorption measurements in the OASIS 2007 dataset, we also calculated the particulate backscattering to attenuation ratio $b_{b p}(\lambda) / c_{p}(\lambda)$. This ratio is a similar proxy for composition as the backscattering ratio [67].

\section{RESULTS AND DISCUSSION}

\section{A. Particle Size Distributions}

Sample PSD for both OASIS 2007 and 2009 are shown in Fig. 3. OASIS 2007 areal PSDs were characterized most prominently by a population of $5-10 \mu \mathrm{m}$ particles, falling off sharply for smaller particle sizes. It is likely that the $5-10 \mu \mathrm{m}$ particles were tightly bound micro-aggregates composed of resuspended fine sediments, pico/nano-plankton, and detritus [28]. A second, more varying, population with a mode of $100-200 \mu \mathrm{m}$ (likely larger aggregates) was superposed on the $5-10 \mu \mathrm{m}$ population. This second population ranged from essentially not present, suggesting a unimodal particle population, to similar concentration (in terms of suspended cross sectional area) as the 5-10 $\mu \mathrm{m}$ modal population. The dynamics of this aggregate population could have been due to particle processes (aggregation, disaggregation, reuspension, and settling) acting within the water column to transfer mass between the two modes; or these larger particles could have been mobilized from a "fluff" layer on the seabed [68].
Most of the OASIS 2009 size spectra did not exhibit the strong bimodality as in 2007 . There did appear to be a similar, strong $5-10 \mu \mathrm{m}$ mode, as well as weaker modes at $\sim 20 \mu \mathrm{m}$ and $\sim 100 \mu \mathrm{m}$. These weaker modes apparently covaried in such a way that the overall behavior appeared roughly as a power law of 5-100 $\mu \mathrm{m}$ (linear in log space), with strong variation of the slope through the deployment. In the largest size bins, some spectra had very steep rising tails for sizes $>200 \mu \mathrm{m}$, consistent with a particle population outside of the size range of the LISST-100X. Based on merged particle size spectra from a digital floc camera and LISST-100X covering maximum particle sizes $>1 \mathrm{~mm}$ [7], the OASIS 2009 data from yearday 289.5 to 290.5 were characterized by high floc fractions approaching $100 \%$ of the volume concentration [69].

\section{B. Variation of Optical Proxies for Particle Composition}

Time series of optical proxies for composition during the OASIS 2009 deployment are shown in Fig. 4. The first half of the deployment was characterized by strong resuspension (Fig. 2), with high values of particulate backscattering ratio $\left(\tilde{B}_{p} \sim 0.04\right)$ indicating that inorganic or mineral composition dominated. However, the chlorophyll concentration was also very high during this period, and our observations spanning approximately $4-8 \mathrm{mgm}^{-3}$ were similar to the extracted chlorophyll measurements made at the MVCO site by Sosik [70].

The full range of spectral variability of $\bar{\omega}_{p}(\lambda)$ is shown in Fig. 5 in gray. We selected three characteristic compositional cases denoted by symbols in the figure: (i) strong resuspension with high scattering as well as nonalgal particle absorption (yearday 289.7, red circles), and two less energetic cases during the second half of the deployment; (ii) low chlorophyll, dominated by nonalgal particles (yearday 293.0, yellow squares); and (iii) higher chlorophyll (yearday 294.9, blue diamonds). In all cases there was a characteristic chlorophyll absorption dip
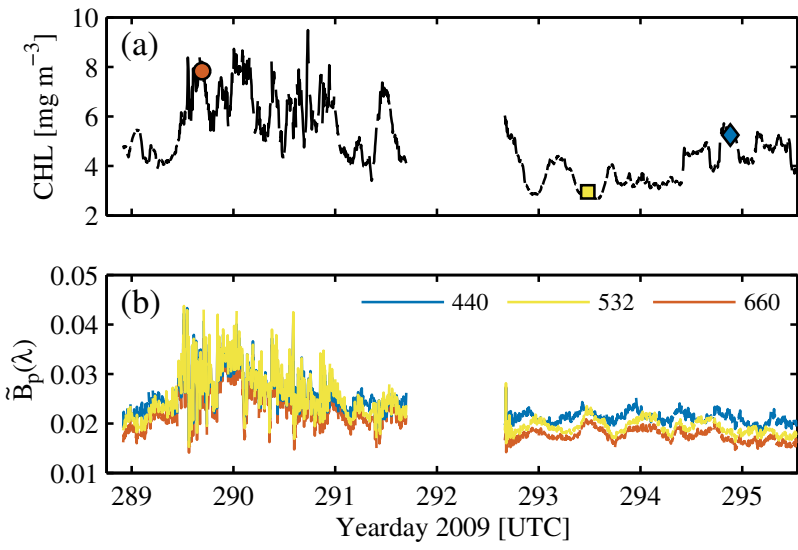

Fig. 4. Time series of particle composition proxies for the OASIS 2009 deployment shown in Fig. 2. (a) Chlorophyll concentration derived using the absorption line height in Eq. (10). (b) Particle backscattering ratio at $\lambda=440,532$, and $660 \mathrm{~nm}$. Points corresponding to characteristic cases (see text and Fig. 5) are shown in (a) as superimposed symbols: red circle, resuspension-dominated; yellow square, less energetic with low chlorophyll; blue diamond, less energetic with higher chlorophyll. 


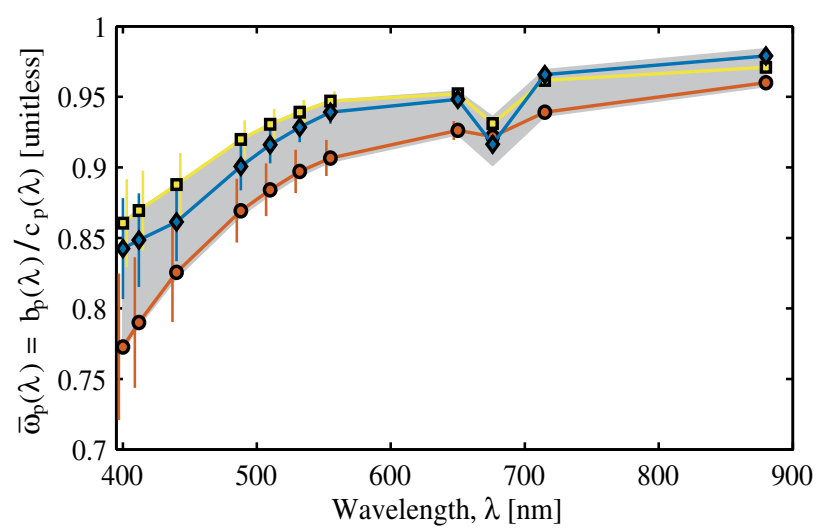

Fig. 5. Particulate single scattering albedo, $\bar{\omega}_{p}(\lambda)$, as a function of wavelength during OASIS 2009. The gray region shows the total range of variability in the dataset, and the symbols show compositional cases selected from the dataset [see Fig. 4(a)]: red circles, resuspensiondominated; yellow squares, less energetic with low chlorophyll; blue diamonds, less energetic with higher chlorophyll.

visible at $676 \mathrm{~nm}$, and in case (iii) there was also a noticeable shoulder at $440 \mathrm{~nm}$ due to relatively higher algal absorption.

The time series of $b_{b p}(532) / c_{p}(532)$ for OASIS 2007 is shown in Fig. 6(a), with highest values of the ratio during resuspension events, similar to our observations of $b_{b p}(532) / b_{p}(532)$ during OASIS 2009 [Fig. 4(b)]. The distribution of the ratio $b_{b p}(532) / c_{p}(532)$ was similar in both the OASIS 2007 and 2009 datasets [Fig. 6(b)], exhibiting similar log-normal-like distributions, with median values of 0.0196 and 0.0194 , 5th percentiles of 0.0138 and 0.0162 , and 95th percentiles values of 0.0326 and 0.0305 for the OASIS
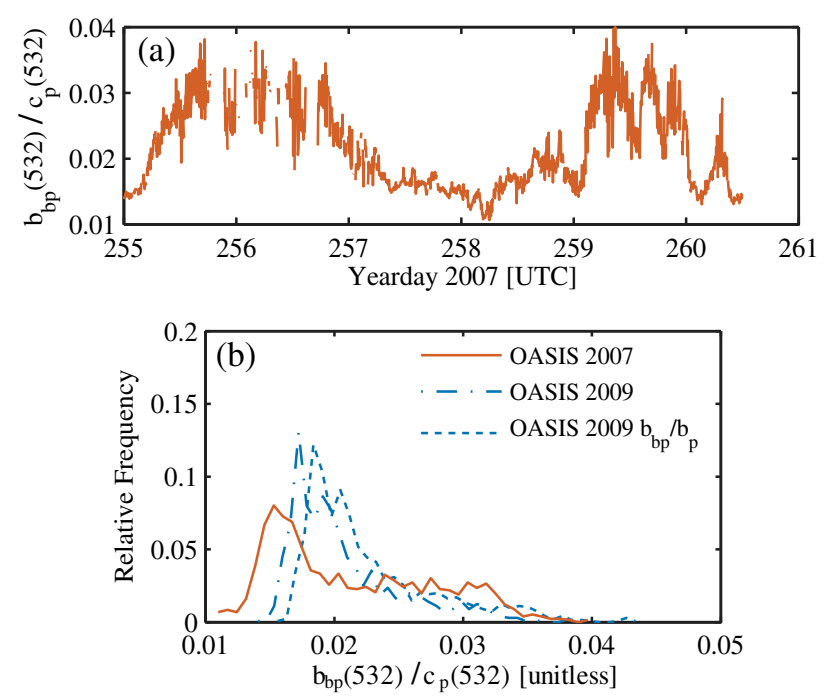

Fig. 6. (a) Time series of particulate backscattering to attenuation ratio, $b_{b p}(532) / c_{p}(532)$, during the OASIS 2007 deployment shown in Fig. 1 used as a proxy for particle composition. (b) Comparison of $b_{b p}(532) / c_{p}(532)$ for the OASIS 2007 and 2009 deployments showing similar log-normal-like distribution. A comparison of $b_{b p}(532) / c_{p}(532)$ and $b_{b p}(532) / b_{p}(532)$ for the OASIS 2009 deployment demonstrates that the two proxies have very similar but offset distributions, as expected for scattering-dominated measurements.
2007 and 2009 datasets, respectively. The lower values of $b_{b p}(532) / c_{p}(532)$ during OASIS 2007 suggested a more organic composition during the less energetic period between resuspension events compared to OASIS 2009. As an example of the similarity between $b_{b p}(532) / c_{p}(532)$ and $b_{b p}(532) /$ $b_{p}(532)$, both distributions are plotted in Fig. 6(b).

\section{Spectral Slopes and Relationship to Particle Size}

Measured particulate attenuation spectra, $c_{p}(\lambda)$, are typically well approximated by power law functions $[30,32]$. For our data, the percent error for each wavelength was calculated as

$$
\% \operatorname{Err}(\lambda)=\frac{\left|\hat{c}_{p}(\lambda)-c_{p}(\lambda)\right|}{c_{p}(\lambda)},
$$

where $\hat{c}_{p}(\lambda)$ is the power-law-modeled particulate beam attenuation spectra. Agreement between the power law model and measured attenuation spectra was very good, with 95 th percentile of $\% \operatorname{Err}(\lambda)$ for each channel in the range of $0.5 \%-1.9 \%$ for the OASIS 2007 data and $0.1 \%-0.9 \%$ for the OASIS 2009 data.

Backscattering did not appear to be as smooth of a power law function of wavelength as beam attenuation, as shown in Fig. 7. Despite the shape of backscattering spectra, power law fits were reasonable, with 95th percentile of $\% \operatorname{Err}(\lambda)$ for each channel in the range of $4.6 \%-24 \%$ (max $17 \%$ excluding the $400 \mathrm{~nm}$ channel) for the OASIS 2007 data and $4.3 \%-15 \%$ for the OASIS 2009 data. Residuals for the fit are shown in Figs. 8(a) and 8(b). Since particulate absorption is expected to cause a dip in the backscattering toward the blue, residuals from a power law fit are expected to have a broad maximum with dips toward the blue and red. In general, the residuals from the field data had this expected shape. However, the sharpness of the residuals may also have been due to an improper BB9 calibration scale factor. Additionally, for the 2009 dataset [where $a_{p}(\lambda)$ was available], the sum of the absolute residuals was found to be correlated with the shape of $a_{p}(\lambda)$ in the blue, in terms of the slope $(m)$ of the linear fit to $a_{p}(\lambda)=m \lambda+b$ for $\lambda=[412,440,488,510,532$, and 555] nm (more negative
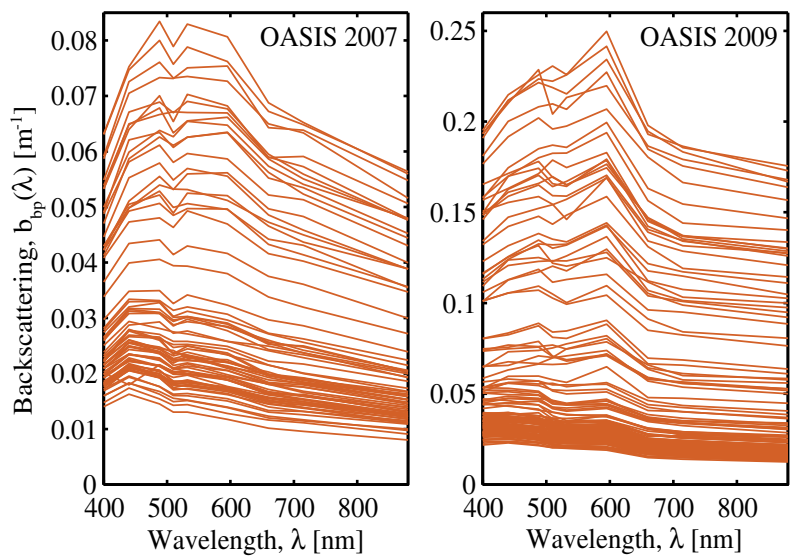

Fig. 7. Backscattering spectra for OASIS 2007 and 2009 deployments. Only spectra where there were no saturated channels are shown (and for clarity, only every tenth). In general, spectra exhibit a broad maximum in the blue-green and decrease into the blue and red-NIR. Note different ordinate ranges. 

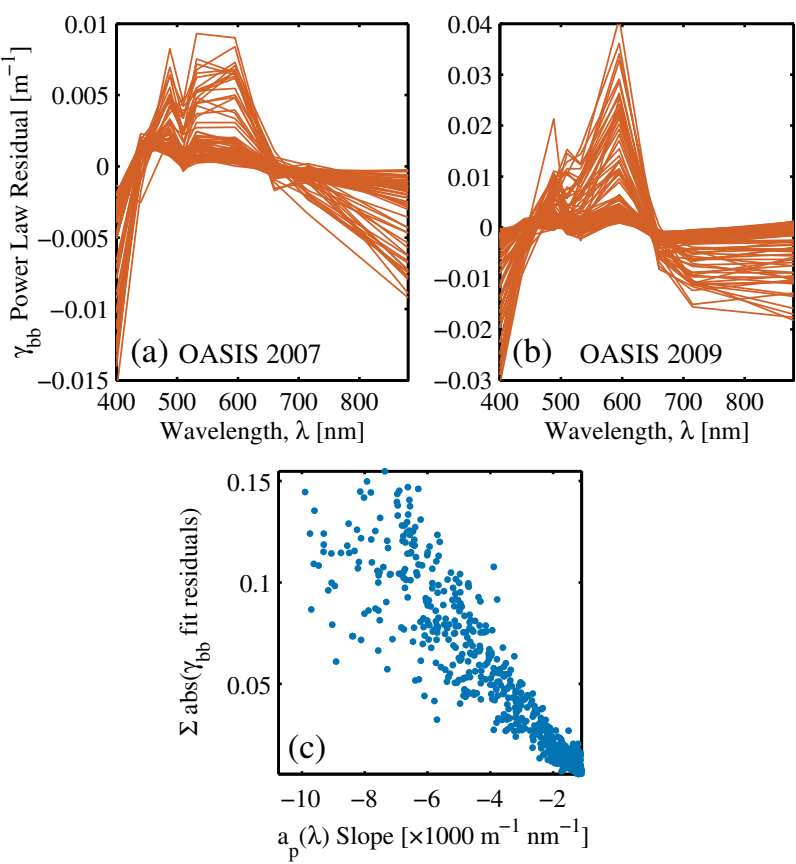

Fig. 8. (a), (b) Residuals of power law fits to the backscattering spectra shown in Fig. 7. Sharp deviation from a smooth residual is likely an indication of an improper BB9 calibration scale factor. Note different scales in (a) and (b). (c) Sum of absolute residuals as a function of particulate absorption spectral shape ( $m$ from linear fit to $a_{p}(\lambda) \propto$ $m \lambda$ for $\lambda=[412,440,488,510,532$, and 555] nm channels; more negative indicates steeper absorption) for the OASIS 2009 dataset.

indicates steeper absorption in the blue). This correlation [Fig. 8(c), $R^{2}=0.89$ ] was consistent with the hypothesis that nonpower law variability in the spectral backscattering shape is driven by the shape of particulate absorption. The sum of absolute residuals was used due to the observation that as overall goodness of fit decreases, the tendency is for negative residual in the lower blue channels and positive residual in the bluegreen hump.

The spectral slope, $\gamma$, of the particulate beam attenuation appeared linearly related to $D_{\text {avg }}$ derived from LISST-100X PSD data (Fig. 9) and was consistent for both 2007 and 2009 deployments. Linear fits to $\gamma$ versus $D_{\text {avg }}$ were performed using a type- 2 major axis regression and were evaluated based on the coefficient of determination $\left(R^{2}\right)$ and normalized root mean square deviation (NRMSD), defined as

$$
\mathrm{NRMSD}=\frac{\left(\frac{1}{N} \sum_{k=1}^{N}\left(\hat{y}_{k}-y_{k}\right)^{2}\right)^{\frac{1}{2}}}{\max (y)-\min (y)},
$$

where $y_{k}, \hat{y}_{k}$, and $N$ are the data, regression estimate, and the number of data, respectively.

Departure from the linear model in 2009 [Fig. 9(a)] coincided with a period where particles larger than $\sim 80 \mu \mathrm{m}$ dropped off sharply causing a decrease in $D_{\text {avg }}$, while the PSD slope for particles $<50 \mu \mathrm{m}$ roughly followed a power law. This is significant in that the large particles $>50 \mu \mathrm{m}$ have reduced influence on $\gamma$ due to the acceptance angle of the ac-9 (the acceptance angle of a transmissometer effectively serves as a
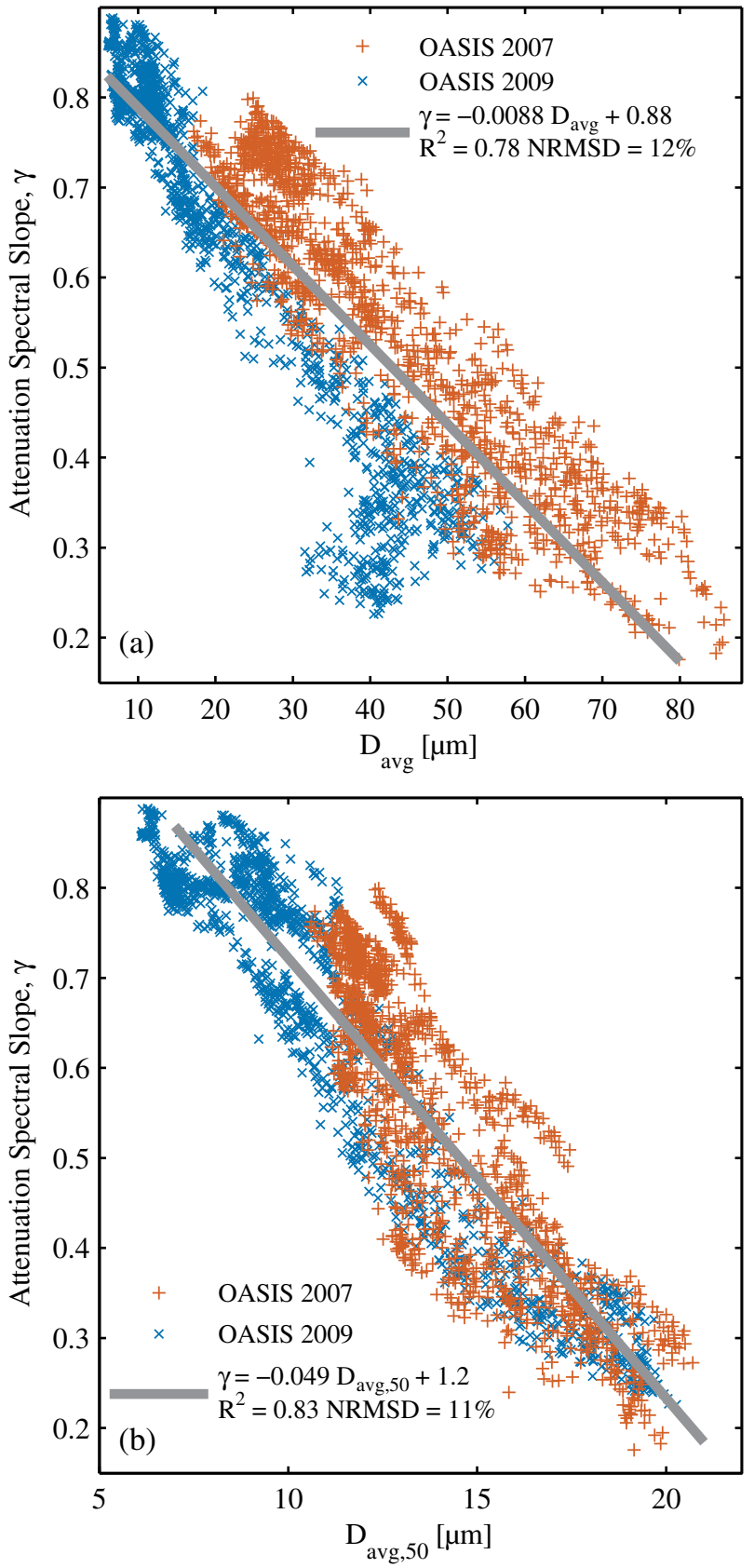

Fig. 9. (a) Attenuation spectral slope as a function of average suspended particle size. (b) Same as above but for an average particle size calculated for particles $<50 \mu \mathrm{m}\left(D_{\text {avg, 50 }}\right)$. Gray lines are type- 2 major axis regressions, and the goodness of fit is expressed as $R^{2}$ and the normalized root mean square deviation (NRMSD, see text).

"filter" on size) but do affect $D_{\text {avg }}$ from the LISST-100X. Boss et al. [71] calculated the effect of acceptance angle on measured beam attenuation and found that for the ac- 9 instrument that less than half of true scattering is measured for particles greater than $\sim 50 \mu \mathrm{m}$ (their Fig. 2), suggesting an approximate cutoff for the maximum particle size that affects $\gamma$. We saw an improvement in the relationship $\left(R^{2}=0.83\right.$, NRMSD $=11 \%$ ) between $D_{\text {avg }}$ and $\gamma$ when the average size was calculated for particles less than $50 \mu \mathrm{m}\left[D_{\text {avg,50, }}\right.$, Fig. 9(b)]. 


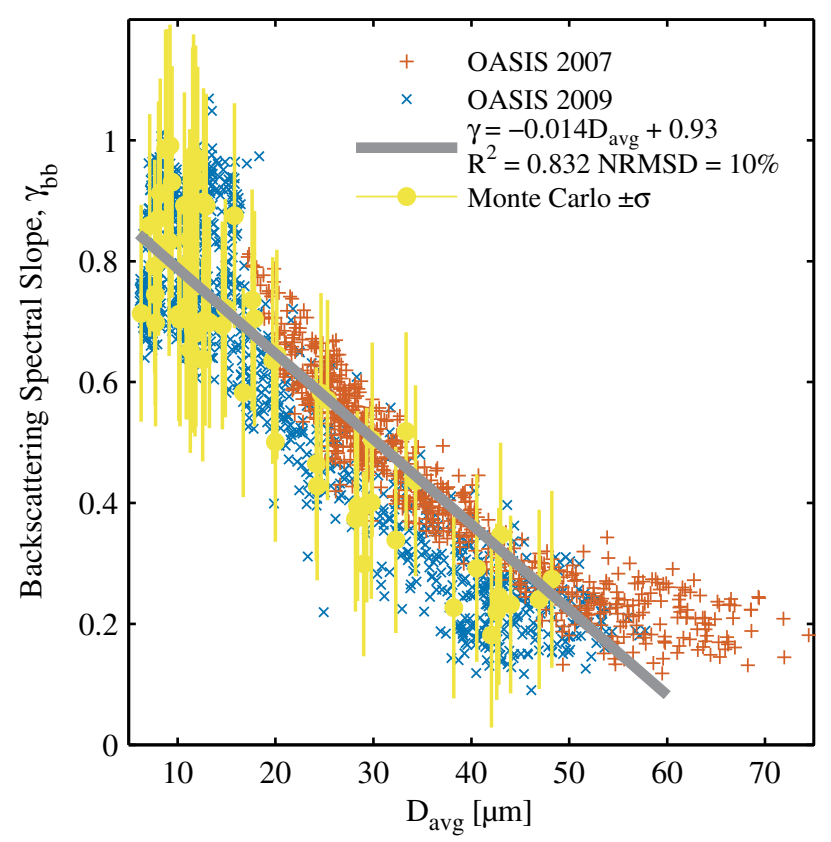

Fig. 10. Backscattering spectral slope as a function of average suspended particle size. Gray lines are type- 2 major axis regressions, and the goodness of fit is expressed as $R^{2}$ and the normalized root mean square deviation (NRMSD, see text). Error bars represent propagated uncertainty of $\pm \sigma$ in $\gamma_{b b}$ from the Monte Carlo model.

The strength of the proxy relationship between $\gamma_{b b}$ and $D_{\text {avg }}$ was also strong $\left(R^{2}=0.83, \mathrm{NRMSD}=10 \%\right)$ and not affected by the acceptance angle issue as was attenuation (Fig. 10). Results of a Monte Carlo analysis (described in Appendix A) on a subset $(N=64)$ of the OASIS 2009 data is overlaid on the plot as an indication of the uncertainty in $\gamma_{b b}$ across the range of observations.

Comparison of the power law fit of scattering to attenuation is shown in Fig. 11(a) and is very tight (NRMSD =1.9\%) with a slope of 1.1 and an offset of -0.3 which compares well with the relationship found in Boss et al. [72]. The slope of power law fit to backscattering, $\gamma_{b b}$, also compares well with the slope of attenuation $\gamma\left(\gamma_{b b}=1.5 \gamma-0.44, R^{2}=0.77\right.$, NRMSD $=13 \%$; not shown) and to the slope of scattering, $\gamma_{b}\left[R^{2}=0.82\right.$, NRMSD $=12 \%$; Fig. $\left.11(\mathrm{~b})\right]$. A nonunity slope of the $\gamma_{b b}$ versus $\gamma_{b}$ relationship could indicate a spectrally varying particulate backscattering ratio. However, caution should be used in the interpretation of the slope and offset of this relationship due to instrumental artifacts such as the effect of acceptance angle on the scattering coefficient derived from beam attenuation [71] and the small sample volume of the backscattering measurements [21]. Both artifacts effectively limit the upper size limit of particles observed, each with their own size cutoff.

\section{Expected and Observed Spectral Variability}

Two frameworks for considering theoretical or modeling nonpower law spectral variability in backscattering can be considered: (1) direct simulation of optical properties, and (2) semi-analytical formulation in terms of customary component IOP models.
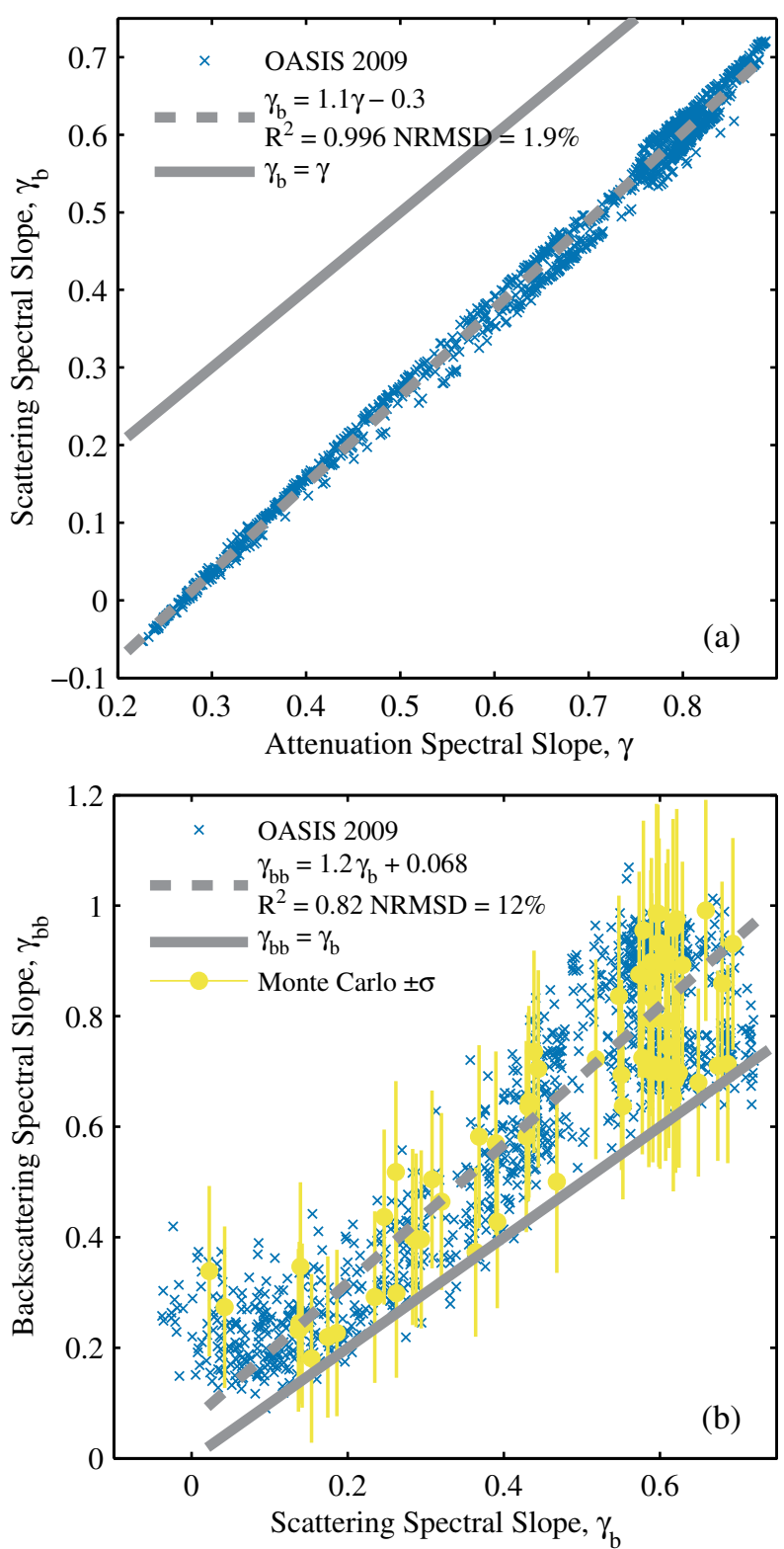

Fig. 11. Particulate scattering spectral slope, $\gamma_{b}$, as a function of attenuation spectral slope, $\gamma$. (b) Particulate backscattering spectral slope, $\gamma_{b b}$, as a function of scattering spectral slope, $\gamma_{b}$. Solid and dashed gray lines are the $1: 1$ and type-2 major axis regressions, respectively. The goodness of fit is expressed as $R^{2}$ and the normalized root mean square deviation (NRMSD, see text). Error bars represent the propagated uncertainty of $\pm \sigma$ in $\gamma_{b b}$ from the Monte Carlo model.

The direct simulation framework considers mathematical models of particle optical properties that compute the backscattering cross section, such as Mie theory for homogenous spheres, as well as more complex methods such as multilayer spheres, symmetric nonspherical particles (T-matrix), discrete dipole approximation (DDA), and improved geometric optics model (IGOM). For oceanic particles, most of these techniques are computationally limited to small particles, and Mie theory is commonly used as it offers the best balance of computational efficiency and numerical stability over the relevant size range. 
However, Mie theory has also been shown to have limited applicability in studies of nonspherical, nonhomogenous particles [73-77]. Furthermore, all of these methods calculate single particle optical properties as a function of size, shape, composition, etc., which then must be weighted by the PSD to calculate the optical properties of the bulk suspension. This represents an additional complication in that some model for PSD must be assumed. Furthermore, particle type across the size spectrum is also expected to vary significantly, and different models or model parameterizations must likely be used for the various particle types. This presents a tremendous challenge in terms of computation and development of realistic models.

A semi-analytical framework can also be used to explore the expected variation in spectral backscattering in terms of a set of measured, typical optical properties. A simple estimate of the spectral backscattering coefficient can be expressed as the product of the particulate backscattering ratio, $\tilde{B}_{p}$ (assumed wavelength-independent [78]), and the particulate scattering coefficient, $b_{p}(\lambda)$, or in terms of beam attenuation, $c_{p}(\lambda)$, as

$$
\hat{b}_{b p}(\lambda)=\tilde{B}_{p} b_{p}(\lambda)=\tilde{B}_{p} \bar{\omega}_{p}(\lambda) c_{p}(\lambda)
$$

In each case, the expected backscattering was calculated per Eq. (13), using a spectrally flat $\tilde{B}_{p}$ determined from the mean of the measured $b_{b p}(\lambda)$ and $b_{p}(\lambda)$ spectra. The expected spectra are shown in Figs. 12(i)-12(iii), with the higher absorption resuspension-dominated case [Fig. 12(i)] exhibiting a roll-off into the blue, and the less energetic cases [Figs. 12(ii) and 12(iii)] nearly linear with wavelength. A significant source of uncertainty in these estimates was due to the uncertainty in the scattering correction of particulate absorption. BB9 backscattering
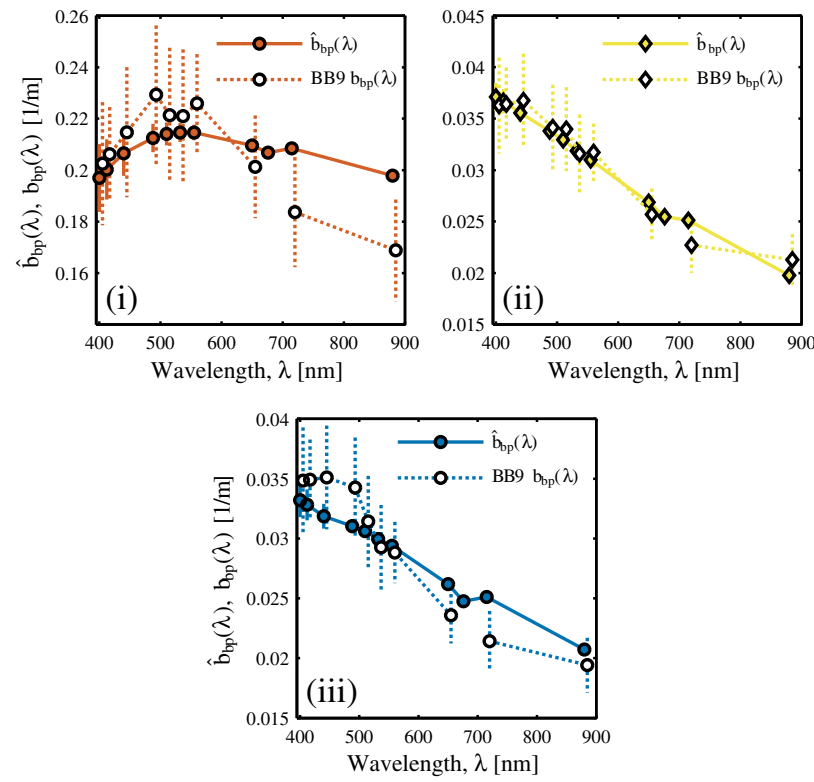

Fig. 12. Comparison of estimated (colored symbols, solid line) and measured (white symbols, dashed line) backscattering spectra for each of the characteristic compositional cases described in Section 3.B: (i) resuspension dominated, (ii) less energetic with low chlorophyll, and (iii) less energetic with higher chlorophyll. Error bars for each represent the propagated uncertainty of $\pm \sigma$ in $b_{b p}(\lambda)$ from the Monte Carlo model. spectra measured at the times corresponding to each case are also shown in Figs. 12(i)-12(iii) with uncertainties calculated using the same Monte Carlo code discussed previously. Qualitative agreement between measured and expected spectral characteristics was reasonable, with the same characteristic blue roll-off and linear behaviors. Measurements agreed with expected values well within levels of uncertainty, except for disagreement in the 715 and $880 \mathrm{~nm}$ channels for the resuspension-dominated case, where BB9 measurements underestimate. In general, we have less confidence in these measurements at 715 and $880 \mathrm{~nm}$ : (1) BB9 calibration is more difficult for these channels due to the low scattering signals of the $2 \mu \mathrm{m}$ microspheres, (2) a higher error in scattering correction at $715 \mathrm{~nm}$ due to the approximately $\pm 30 \%$ uncertainty in the empirical correction used to estimate true absorption at $715 \mathrm{~nm}$ from ac9 measured $a_{p, m}(715)$ [54], and (3) extrapolation of absorption data from 715 to $880 \mathrm{~nm}$.

Spectral disagreement in these two comparisons could point to possible spectral variability in the particulate backscattering ratio, $\tilde{B}_{p}$. The spectral nature of $\tilde{B}_{p}$ remains an item of debate within the ocean optics community, largely due to the lack of multispectral volume scattering function measurements, leaving most comparisons to be made on backscattering estimated from scattering at a single angle in the backward direction. This ratio is predicted by Mie theory to be spectrally flat for power law size populations of homogenous spheres [78], which is supported by some studies $[79,80]$. However, other studies have suggested spectral variability of the backscattering ratio, especially in more turbid coastal waters $[63,81]$. The particulate backscattering ratio calculated from the measured $b_{b p}(\lambda)$ and $b_{p}(\lambda)$ for the characteristic cases is shown in Fig. 13. Spectral dependence in all three cases is weak and mostly within the uncertainty estimates for each channel. The most significant spectral variability within the visible wavelengths occurs in the less-energetic high-chlorophyll case (iii).

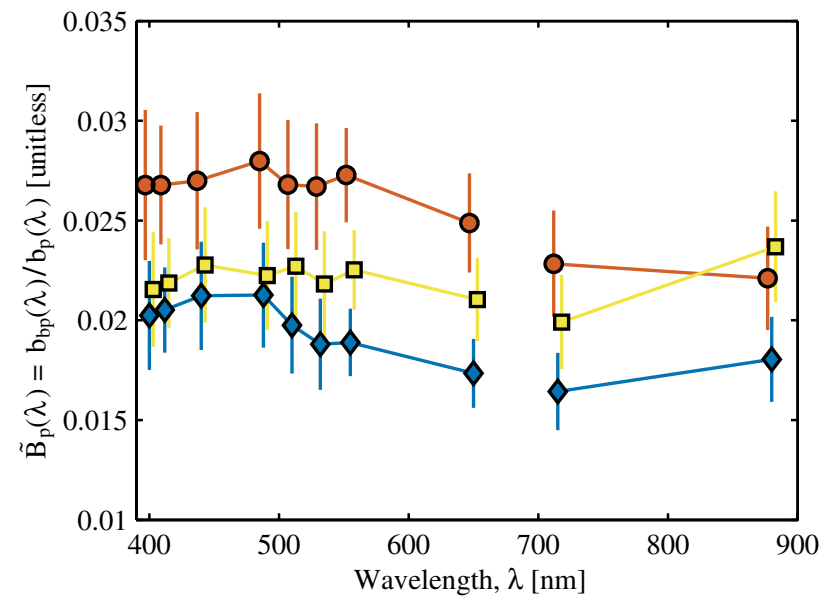

Fig. 13. Spectral backscattering ratio, $\tilde{B}_{p}(\lambda)$, calculated using ac- 9 and $\mathrm{BB} 9$ measurements for the three characteristic compositions described in Section 3.B: red circles, resuspension-dominated; yellow squares, less energetic with low chlorophyll; blue diamonds, less energetic with higher chlorophyll. The error bars represent uncertainty of $\pm \sigma$ in both $b_{b p}(\lambda)$ and $b_{p}(\lambda)$ from the Monte Carlo model. 


\section{CONCLUSION}

Theoretical tools have been an indispensable foundation of ocean optics for decades but are usually limited by assumptions about particle size, shape, and composition (e.g., power law size distribution of homogenous spheres characterized by an index of refraction for the entire population). Such models for power law distributions of homogenous nonabsorbing spheres predict that the spectral slopes of backscattering and attenuation should be a proxy for the power law slope of the particle size distribution. To avoid the assumptions of theoretical methods, we empirically examined the relationship between particle size distribution and spectral shape of attenuation and backscattering directly with co-located and co-incident attenuation, backscattering, and particle sizing instrumentation.

Our results suggest that spectral slopes of attenuation and backscattering can be used to infer changes in particle size, at least for nonalgal particle dominated cases such as coastal, river-plume, and bottom boundary layer waters. Future work should include a similar investigation of a wider range of conditions, especially algal-dominated waters.

The observed relationship was further validated using a Monte Carlo analysis including uncertainties due to instrument calibration and ac-9 scattering correction. As a test of closure, the measured backscattering and scattering spectra for endmember cases were found to be in agreement well within the level of propagated uncertainty, except for the high absorption case NIR channels, where instrumental and methodological uncertainties are more significant and not accounted for in the Monte Carlo model. Our measurements may indicate significant spectral variability of the particulate backscattering ratio. However, conclusive determination is difficult given instrumental and methodological uncertainies.

\section{APPENDIX A: UNCERTAINTY IN BACKSCATTERING MEASUREMENTS}

Sources of uncertainty in spectral backscattering measurements derived from Eqs. (5), (6), and (8) include: (i) calibration uncertainty in the scale factor, $s(\lambda)$, and dark readings, $d(\lambda)$; (ii) path length attenuation correction, $K(\lambda)$, uncertainty due to the scattering correction of ac-9 absorption measurements; (iii) uncertainty in the relationship between the backscattering coefficient and the measurement of the scattering at a single angle, $\chi_{p}\left(124^{\circ}\right)$; and (iv) uncertainty in the seawater volume scattering function, $\beta_{\mathrm{sw}}\left(\lambda, 124^{\circ}\right)$. Propagated uncertainties in spectral scattering, $b_{p}(\lambda)$, backscattering, $b_{b p}(\lambda)$, and spectral slope, $\gamma_{b b}$, were estimated using a Monte Carlo approach with inputs summarized in Table 1. Details on the scale factor and scattering correction uncertainties and the Monte Carlo approach are described below.

Uncertainties in the calibration scale factors arise primarily from ignorance of the angular weighting functions, $W(\theta)$, for an individual instrument, choice of microsphere diameter for calibration, traceability of microsphere size distribution, and unknown exact LED wavelength to be used in Mie calculations [56]. Estimated uncertainty in the scale factor due to the angular weighting function and microsphere standard selection is $\sim 5 \%-10 \%$ and for nonnominal LED wavelengths is $\sim 5 \%$. This $\sim 7 \%-11 \%$ combined (additive) uncertainty in the scale
Table 1. Parameters and Uncertainties Used in the Monte Carlo Analysis of Backscattering Uncertainty ${ }^{2}$

\begin{tabular}{lcc}
\hline Parameter & Uncertainty, $\boldsymbol{\sigma}$ & References \\
\hline$d(\lambda)$ & 2 counts & Estimated \\
$s(\lambda)$ & $11 \%$ & {$[56]$} \\
$\epsilon_{\mathrm{sc}}(440)$ & $20 \%$ & Described in text \\
$\chi_{p}\left(124^{\circ}\right)$ & $4 \%$ & {$[56,60]$} \\
$\beta_{\mathrm{sw}}\left(\lambda, 124^{\circ}\right)$ & $2.5 \%$ & {$[61,62]$} \\
\hline
\end{tabular}

${ }^{a}$ All uncertainties except scattering correction error, $\epsilon_{\text {sc }}(\lambda)$, are spectrally independent.

factor is not expected to be spectrally dependent, due to the highly variable structure in the weighting functions for $2 \mu \mathrm{m}$ microspheres and the random nature of LED nominal wavelength inaccuracy $(\Delta \lambda$ varies and for each channel independently). Uncertainty in the NIR $(880 \mathrm{~nm})$ channel on our ECO BB9 instrument may have been higher due to low scattering by microspheres at that wavelength. Drift in the scale factor is typically $\sim 2 \%-10 \%$ per year for ECO BB-style sensors, due to dimming of the LEDs over time. More severe drift in the blue channels has been attributed to "yellowing" of the optical epoxy in these sensors, and temperature has also been shown to significantly affect instrument response for the red LED channels. Dark offsets were not measured in the field before the deployments, but typical differences observed between factory and field dark offsets are small ( $\sim 2$ counts) and not spectrally dependent. These details of WET Labs ECO BB uncertainty are from the review by Sullivan et al. [56] (and via a personal communication [82]) and have also been discussed by Dall'Olmo et al. [83] and Twardowski et al. [84]. Drift was not considered in this uncertainty analysis due to instrument recalibration prior to each OASIS deployment.

In most environments, the pathlength correction described by Eq. (6) is negligible. For example, an absorption of $a_{p g}(412) \sim 0.5 \mathrm{~m}^{-1}$ (typical of coastal waters) would result in an $\sim 1.0 \%$ underestimation of particulate backscattering at that wavelength. However, strong nonalgal particle absorption present in the OASIS dataset $\left[a_{p g}(412) \sim 0.4-2.6 \mathrm{~m}^{-1}\right.$ for OASIS 2009, as a result of corrections approaching 5\%] has the potential of contributing a spectral bias that would affect $\gamma_{b b}$. To first order, particle resuspension increases the mean particle size and total amount of material in suspension. This could have hypothetically led to the correlation of the spectral shape of backscattering with particle size due to the pathlength correction, rather than true spectral variability in particulate backscattering, warranting close consideration of uncertainty in the scattering correction. The "proportionale" scattering correction presented in Röttgers et al. [54] has uncertainties of $~ 10 \%$ in most visible channels across a wide range of conditions and approximately $20 \%-30 \%$ in channels where absorption tends to be low, such as $715 \mathrm{~nm}$. The relative error presented in their Fig. 8 does not show a strong spectral dependence. However, for our analysis we assumed a worst case scenario where the error in scattering correction results in a spectrally dependent particulate absorption $a_{p}^{\prime}(\lambda)=a_{p}(\lambda) \epsilon_{\mathrm{sc}}(\lambda)$, where $\epsilon_{\mathrm{sc}}(\lambda) \sim \lambda^{\eta}$.

The Monte Carlo distribution of the scattering correction error, $\epsilon_{\mathrm{sc}}(\lambda)$, was defined using a normal distribution of the relative error in absorption $\epsilon_{s c}(440)=a_{p}^{\prime}(440) / a_{p}(440)$, 
$\sigma_{\epsilon_{\mathrm{sc}}(440)}=20 \%$, based on a conservative estimate of the error in visible channels from Röttgers et al. [54] (their Fig. 8). The slope of the scattering correction error, $\eta$, is defined for each Monte Carlo realization so that $\epsilon_{\mathrm{sc}}(880)=0$. Note also that conservative estimation of the scattering correction error will also cover uncertainty in the BB9 attenuation factor, $K(\lambda)$. All other input parameters were varied with spectrally independent normal distributions with the specified input uncertainties. Monte Carlo analysis was run on a subset of the data $(5 \%, N=64)$ with $15 \times 10^{3}$ Monte Carlo realizations simulated for each data point (doubling the number of realizations was not found to be significantly different in terms of the mean and standard deviation of the resulting $\gamma_{b b}$ ).

Funding. National Aeronautics and Space Administration (NASA) (NNX13AC42G); Office of Naval Research (ONR) (N00014-04-1-0235, N00014-10-1-0508).

Acknowledgment. We sincerely thank the WHOI engineers, support staff, and divers that worked closely with us at the MVCO to make the OASIS project possible. To name a few: Janet Fredericks, Jay Sisson, Steve Falutico, and Andy Girard; the captains and crews of the R/V Tioga and R/V Connecticut; and the MVCO Data Management Office for making core instrument, including $\mathrm{ADCP}$, data publically available. Grace Chang and Tommy Dickey (UCSB) loaned us the LISST-100X used in 2009. Jim Loftin from the University of Maine provided countless hours of assistance in experimental design and logistics for the OASIS project. We thank our colleagues Paul Hill, Kristian Curran, John Newgard (Dalhousie University), Tim Milligan, Brent Law (Bedford Institute of Oceanography), and John Trowbridge (WHOI) for a productive collaboration during the OASIS project. Early versions of this manuscript benefited in particular from discussions with Paul Hill and comments from Curtis Mobley and Ivona Cetinić. We also thank Mike Twardowski, James Sullivan, and one anonymous reviewer for thoughtful reviews that have improved the quality of this paper.

\section{REFERENCES}

1. L. Karp-Boss, L. Azevedo, and E. Boss, "LISST-100 measurements of phytoplankton size distribution: evaluation of the effects of cell shape," Limnol. Oceanogr. Methods 5, 396-406 (2007).

2. K. Kranck and T. G. Milligan, "Grain size in oceanography," in Principles, Methods and Application of Particle Size Analysis, J. P. M. Syvitski, ed. (Cambridge University, 1991), Chap. 23, pp. 332-345.

3. Y. Agrawal and H. Pottsmith, "Instruments for particle size and settling velocity observations in sediment transport," Mar. Geol. 168, 89-114 (2000).

4. T. Serra, J. Colomer, X. Cristina, X. Vila, J. Arellano, and X. Casamitjana, "Evaluation of laser in situ scattering instrument for measuring concentration of phytoplankton, purple sulfur bacteria, and suspended inorganic sediments in lakes," J. Environ. Eng. 127, 1023-1030 (2001)

5. D. C. Fugate and C. T. Friedrichs, "Determining concentration and fall velocity of estuarine particle populations using ADV, OBS and LISST," Cont. Shelf Res. 22, 1867-1886 (2002).

6. G. Voulgaris and S. T. Meyers, "Temporal variability of hydrodynamics, sediment concentration and sediment settling velocity in a tidal creek," Cont. Shelf Res. 24, 1659-1683 (2004).
7. O. A. Mikkelsen, P. S. Hill, T. G. Milligan, and R. J. Chant, "In situ particle size distributions and volume concentrations from a LISST100 laser particle sizer and a digital floc camera," Cont. Shelf Res. 25, 1959-1978 (2005).

8. C. F. Jago, S. E. Jones, P. Sykes, and T. Rippeth, "Temporal variation of suspended particulate matter and turbulence in a high energy, tide-stirred, coastal sea: relative contributions of resuspension and disaggregation," Cont. Shelf Res. 26, 2019-2028 (2006).

9. F. Pedocchi and M. H. García, "Evaluation of the LISST-ST instrument for suspended particle size distribution and settling velocity measurements," Cont. Shelf Res. 26, 943-958 (2006).

10. S. Anglès, A. Jordi, E. Garcés, M. Masó, and G. Basterretxea, "Highresolution spatio-temporal distribution of a coastal phytoplankton bloom using laser in situ scattering and transmissometry (LISST)," Harmful Algae 7, 808-816 (2008).

11. G. Neukermans, H. Loisel, X. Mériaux, R. Astoreca, and D. McKee, "In situ variability of mass-specific beam attenuation and backscattering of marine particles with respect to particle size, density, and composition," Limnol. Oceanogr. 57, 124-144 (2012).

12. K. Braithwaite, D. Bowers, W. Nimmo Smith, G. Graham, Y. Agrawal, and O. Mikkelsen, "Observations of particle density and scattering in the Tamar Estuary," Mar. Geol. 277, 1-10 (2010).

13. E. Boss, M. Perry, D. Swift, L. Taylor, P. Brickley, J. Zaneveld, and S. Riser, "Three years of ocean data from a bio-optical profiling float," EOS Trans. Am. Geophys. Union 89, 209-210 (2008).

14. K. S. Johnson, W. M. Berelson, E. S. Boss, Z. Chase, H. Claustre, S. R. Emerson, N. Gruber, A. Körtzinger, M. J. Perry, and S. C. Riser, "Observing biogeochemical cycles at global scales with profilging floats and gliders: prospects for a global array," Oceanography 22, 216-225 (2009).

15. M. J. Behrenfeld and E. Boss, "Beam attenuation and chlorophyll concentration as alternative optical indices of phytoplankton biomass," J. Mar. Res. 64, 431-451 (2006).

16. I. Cetinić, M. J. Perry, N. T. Briggs, E. Kallin, E. A. D’Asaro, and C. M. Lee, "Particulate organic carbon and inherent optical properties during 2008 North Atlantic Bloom Experiment," J. Geophys. Res. 117, C06028 (2012).

17. S. Q. Duntley, "Underwater lighting by submerged lasers and incandescent sources," Technical Report (Scripps Institute of Oceanography, 1971).

18. J. R. Zaneveld and W. Pegau, "Robust underwater visibility parameter," Opt. Express 11, 2997-3009 (2003).

19. H. Bader, "The hyperbolic distribution of particle sizes," J. Geophys. Res. 75, 2822-2830 (1970).

20. J. C. Kitchen, J. R. Zaneveld, and H. Pak, "Effect of particle size distribution and chlorophyll content on beam attenuation spectra," Appl. Opt. 21, 3913-3918 (1982).

21. G. A. Jackson, R. Maffione, D. K. Costello, A. L. Alldredge, B. E. Logan, and H. G. Dam, "Particle size spectra between $1 \mu \mathrm{m}$ and $1 \mathrm{~cm}$ at Monterey Bay determined using multiple instruments," Deep. Sea Res. Part I 44, 1739-1767 (1997).

22. L. Stemmann, D. Eloire, A. Sciandra, G. A. Jackson, L. Guidi, M. Picheral, and G. Gorsky, "Volume distribution for particles between 3.5 to $2000 \mu \mathrm{m}$ in the upper $200 \mathrm{~m}$ region of the South Pacific Gyre," Biogeosciences 5, 299-310 (2008).

23. C. J. Buonassissi and H. M. Dierssen, "A regional comparison of particle size distributions and the power law approximation in oceanic and estuarine surface waters," J. Geophys. Res. 115, 1-12 (2010).

24. R. A. Reynolds, D. Stramski, V. M. Wright, and S. B. Woźniak, "Measurements and characterization of particle size distributions in coastal waters," J. Geophys. Res. 115, 1-19 (2010).

25. J. E. Harris, "Characterization of suspended matter in the Gulf of Mexico-II particle size analysis of suspended matter from deep water," Deep Sea Res. 24, 1055-1061 (1977).

26. K. Kranck and T. Milligan, "Characteristics of suspended particles at an 11-hour anchor station in San Francisco Bay, California," J. Geophys. Res. 97, 11373-11382 (1992).

27. D. Risović, "Two-component model of sea particle size distribution," Deep. Sea Res. Part I 40, 1459-1473 (1993). 
28. O. A. Mikkelsen, P. S. Hill, and T. G. Milligan, "Single-grain, microfloc and macrofloc volume variations observed with a LISST-100 and a digital floc camera," J. Sea Res. 55, 87-102 (2006).

29. A. Morel, "Diffusion de la lumière par les eaux de mer; résultats expérimentaux et approche théorique (Scattering of light by seawater: experimental results and theoretical approach, translated by George Halikas)," in Optics of the Sea, Interface and In-water Transmission and Imaging, Lecture Series No. 61 (NATO AGARD, 1973).

30. P. Diehl and H. Haardt, "Measurement of the spectral attenuation to support biological research in a plankton tube experiment," Oceanol. Acta 3, 89-96 (1980)

31. E. Boss, M. S. Twardowski, and S. Herring, "Shape of the particulate beam attenuation spectrum and its inversion to obtain the shape of the particulate size distribution," Appl. Opt. 40, 4885-4893 (2001).

32. E. Boss, W. S. Pegau, W. D. Gardner, J. R. V. Zaneveld, A. H. Barnard, M. S. Twardowski, G. C. Chang, and T. D. Dickey, "Spectral particulate attenuation and particle size distribution in the bottom boundary layer of a continental shelf," J. Geophys. Res. 106, 9509-9516 (2001).

33. C. S. Roesler and M. J. Perry, "In situ phytoplankton absorption, fluorescence emission, and particulate backscattering spectra determined from reflectance," J. Geophys. Res. 100, 13279-13294 (1995).

34. H. R. Gordon, M. R. Lewis, S. D. McLean, M. S. Twardowski, S. A. Freeman, K. J. Voss, and G. C. Boynton, "Spectra of particulate backscattering in natural waters," Opt. Express 17, 16192-16208 (2009).

35. P. J. Werdell, B. A. Franz, S. W. Bailey, G. C. Feldman, E. Boss, V. E. Brando, M. Dowell, T. Hirata, S. J. Lavender, Z. Lee, H. Loisel, S. Maritorena, F. Mélin, T. S. Moore, T. J. Smyth, D. Antoine, E. Devred, O. H. F. D'Andon, and A. Mangin, "Generalized ocean color inversion model for retrieving marine inherent optical properties," Appl. Opt. 52, 2019-2037 (2013)

36. A. Bricaud and A. Morel, "Light attenuation and scattering by phytoplanktonic cells: a theoretical modeling," Appl. Opt. 25, 571-580 (1986).

37. Y. Ahn, A. Bricaud, and A. Morel, "Light backscattering efficiency and related properties of some phytoplankters," Deep. Res. Part A 39, 1835-1855 (1992).

38. J. R. V. Zaneveld and J. C. Kitchen, "The variation in the inherent optical properties of phytoplankton near an absorption peak as determined by various models of cell structure," J. Geophys. Res. 100, 13309-13320 (1995).

39. H. Loisel, J.-M. Nicolas, A. Sciandra, D. Stramski, and A. Poteau, "Spectral dependency of optical backscattering by marine particles from satellite remote sensing of the global ocean," J. Geophys. Res. 111, 1-14 (2006).

40. T. S. Kostadinov, D. A. Siegel, and S. Maritorena, "Retrieval of the particle size distribution from satellite ocean color observations," J. Geophys. Res. 114, 1-22 (2009).

41. T. S. Kostadinov, D. A. Siegel, and S. Maritorena, "Global variability of phytoplankton functional types from space: assessment via the particle size distribution," Biogeosciences 7, 3239-3257 (2010).

42. T. C. Austin, J. B. Edson, W. R. McGillis, M. Purcell, R. A. Petitt, M. K. McElroy, C. W. Grant, J. Ware, and S. K. Hurst, "A network based telemetry architecture developed for the Martha's Vineyard Coastal Observatory," IEEE J. Ocean. Eng. 27, 228-234 (2002).

43. A. J. Souza, T. D. Dickey, and G. C. Chang, "Modeling water column structure and suspended particulate matter on the Middle Atlantic continental shelf during the passages of Hurricanes Edouard and Hortense," J. Mar. Res. 59, 1021-1045 (2001).

44. G. Chang, T. Dickey, O. Schofield, E. Weidemann, E. Boss, W. Pegau, M. Moline, and S. Glenn, "Nearshore physical processes and bio-optical properties in the New York Bight," J. Geophys. Res. 107, 1-20 (2002).

45. S. Glenn, C. Jones, M. Twardowski, L. Bowers, J. Kerfoot, J. Kohut, D. Webb, and O. Schofield, "Glider observations of sediment resuspension in a Middle Atlantic Bight fall transition storm," Limnol. Oceanogr. 53, 2180-2196 (2008).

46. W. H. Slade, E. Boss, G. Dall'Olmo, M. R. Langner, J. Loftin, M. J. Behrenfeld, C. Roesler, and T. K. Westberry, "Underway and moored methods for improving accuracy in measurement of spectral particulate absorption and attenuation," J. Atmos. Ocean. Technol. 27, 1733-1746 (2010).

47. F. Ferri, G. Righini, and E. Paganini, "Inversion of low-angle elastic light-scattering data with a new method devised by modification of the Chahine algorithm," Appl. Opt. 36, 7539-7550 (1997).

48. ISO, "Particle size analysis-laser diffraction methods (ISO 13320:2009)," Technical Report (2009).

49. P. Traykovski, R. J. Latter, and J. D. Irish, "A laboratory evaluation of the laser in situ scattering instrument using natural sediments," Mar. Geol. 159, 355-367 (1999).

50. Y. C. Agrawal, A. Whitmire, O. A. Mikkelsen, and H. C. Pottsmith, "Light scattering by random shaped particles and consequences on measuring suspended sediments by laser diffraction," J. Geophys. Res. 113, 1-11 (2008).

51. Y. C. Agrawal and O. A. Mikkelsen, "Empirical forward scattering phase functions from 0.08 to $16 \mathrm{deg}$. for randomly shaped terrigenous 1-21 $\mu \mathrm{m}$ sediment grains," Opt. Express 17, 8805-8814 (2009).

52. W. H. Slade, E. Boss, and C. Russo, "Effects of particle aggregation and disaggregation on their inherent optical properties," Opt. Express 19, 7945-7959 (2011).

53. M. Twardowski, J. Sullivan, P. Donaghay, and J. Zaneveld, "Microscale quantification of the absorption by dissolved and particulate material in coastal waters with an ac-9," J. Atmos. Ocean Technol. 16, 691-707 (1999).

54. R. Röttgers, D. McKee, and S. B. Woźniak, "Evaluation of scatter corrections for ac-9 absorption measurements in coastal waters," Methods Oceanogr. 7, 21-39 (2013).

55. E. Boss, W. S. Pegau, M. Lee, M. Twardowski, E. Shybanov, G. Korotaev, and F. Baratange, "Particulate backscattering ratio at LEO 15 and its use to study particle composition and distribution," J. Geophys. Res. 109, 1-10 (2004).

56. J. Sullivan, M. Twardowski, J. Zaneveld, and C. Moore, "Measuring optical backscattering in water," in Light Scattering Reviews 7, A. A. Kokhanovsky, ed. (Springer, 2013), pp. 189-224.

57. E. T. Peltzer, "Model I and Model II Regressions," retrieved 04 April 2015, from http://www.mbari.org/staff/etp3/regress/index.htm.

58. T. Oishi, "Significant relationship between the backward scattering coefficient of sea water and the scatterance at 120 degrees," Appl. Opt. 29, 4658-4665 (1990).

59. R. Maffione and D. R. Dana, "Instruments and methods for measuring the backward-scattering coefficient of ocean waters," Appl. Opt. 36 6057-6067 (1997).

60. E. Boss and W. S. Pegau, "Relationship of light scattering at an angle in the backward direction to the backscattering coefficient," Appl. Opt. 40, 5503-5507 (2001).

61. X. Zhang and L. Hu, "Estimating scattering of pure water from density fluctuation of the refractive index," Opt. Express 17, 1671-1678 (2009).

62. X. Zhang, L. Hu, and M.-X. He, "Scattering by pure seawater: effect of salinity," Opt. Express 17, 5698-5710 (2009).

63. D. McKee, M. Chami, I. Brown, V. S. Calzado, D. Doxaran, and A. Cunningham, "Role of measurement uncertainties in observed variability in the spectral backscattering ratio: a case study in mineral-rich coastal waters," Appl. Opt. 48, 4663-4675 (2009).

64. M. L. Estapa, E. Boss, L. M. Mayer, and C. S. Roesler, "Role of iron and organic carbon in mass-specific light absorption by particulate matter from Louisiana coastal waters," Limnol. Oceanogr. 57, 97-112 (2012)

65. C. S. Roesler and A. H. Barnard, "Optical proxy for phytoplankton biomass in the absence of photophysiology: rethinking the absorption line height," Methods Oceanogr. 7, 79-94 (2014).

66. M. S. Twardowski, E. Boss, J. B. Macdonald, W. S. Pegau, A. H. Barnard, and J. R. V. Zaneveld, "A model for estimating bulk refractive index from the optical backscattering ratio and the implications for understanding particle composition in case I and case II waters," J Geophys. Res. 106, 14129 (2001).

67. E. Boss, L. Taylor, S. Gilbert, K. Gundersen, N. Hawley, C. Janzen, T. Johengen, H. Purcell, C. Robertson, D. Schar, G. Smith, and M. Tamburri, "Comparison of inherent optical properties as a surrogate 
for particulate matter concentration in coastal waters," Limnol. Oceanogr. Methods 7, 803-810 (2009).

68. C. Jago, A. Bale, M. Green, M. Howarth, S. Jones, I. McCave, G Millward, A. Morris, A. Rowden, and J. Williams, "Resuspension processes and seston dynamics, southern North Sea," Philos. Trans. R. Soc. London A 343, 475-491 (1993).

69. P. Hill, Dalhousie University (personal communication, 2011).

70. H. M. Sosik, "Martha's Vineyard Coastal Observatory \& Coastal Phytoplankton Ecology," retrieved 10 April 2015, from http://www .whoi.edu/science/AOPE/dept/COSMOS/Sosik.pdf.

71. E. Boss, W. H. Slade, M. Behrenfeld, and G. Dall'Olmo, "Acceptance angle effects on the beam attenuation in the ocean," Opt. Express 17, 1535-1550 (2009)

72. E. Boss, M. Picheral, T. Leeuw, A. Chase, E. Karsenti, G. Gorsky, L. Taylor, W. Slade, J. Ras, and H. Claustre, "The characteristics of particulate absorption, scattering and attenuation coefficients in the surface ocean; contribution of the Tara Oceans expedition," Methods Oceanogr. 7, 52-62 (2013).

73. S. Asano and M. Sato, "Light scattering by randomly oriented spheroidal particles," Appl. Opt. 19, 962-974 (1980).

74. A. Mugnai and W. J. Wiscombe, "Scattering from nonspherical Chebyshev particles. 1: cross sections, single-scattering albedo, asymmetry factor, and backscattered fraction," Appl. Opt. 25, 1235-1244 (1986).

75. C. F. Bohren and S. B. Singham, "Backscattering by nonspherical particles: a review of methods and suggested new approaches," J. Geophys. Res. 96, 5269-5277 (1991).
76. W. R. Clavano, E. Boss, and L. Karp-Boss, "Inherent optical properties of nonspherical marine-like particles-from theory to observation," Oceanogr. Mar. Biol. 45, 1-38 (2007).

77. X. Zhang, M. Twardowski, and M. Lewis, "Retrieving composition and sizes of oceanic particle subpopulations from the volume scattering function," Appl. Opt. 50, 1240-1259 (2011).

78. O. Ulloa, S. Sathyendranath, and T. Platt, "Effect of the particle-size distribution on the backscattering ratio in seawater," Appl. Opt. 33, 7070-7077 (1994).

79. A. Whitmire, E. Boss, T. Cowles, and W. Pegau, "Spectral variability of the particulate backscattering ratio," Opt. Express 15, 7019-7031 (2007).

80. A. L. Whitmire, W. S. Pegau, L. Karp-Boss, E. Boss, and T. J. Cowles, "Spectral backscattering properties of marine phytoplankton cultures," Opt. Express 18, 15073-15093 (2010).

81. M. Chami, E. B. Shybanov, T. Y. Churilova, G. A. Khomenko, M. E. G. Lee, O. V. Martynov, G. A. Berseneva, and G. K. Korotaev, "Optical properties of the particles in the Crimea coastal waters (Black Sea)," J. Geophys. Res. Oceans 110, 1-17 (2005).

82. J. Sullivan, WET Labs (personal communication, 2015).

83. G. Dall'Olmo, T. K. Westberry, M. J. Behrenfeld, and W. H. Slade, "Significant contribution of large particles to optical backscattering in the open ocean," Biogeosciences 6, 947-967 (2009).

84. M. S. Twardowski, H. Claustre, S. A. Freeman, D. Stramski, and Y. Huot, "Optical backscattering properties of the "clearest" natural waters," Biogeosciences 4, 1041-1058 (2007). 